Article

\title{
Internet of Food (IoF), Tailor-Made Metal Oxide Gas Sensors to Support Tea Supply Chain
}

\author{
Estefanía Núñez-Carmona $^{1}\left(\mathbb{D}\right.$, Marco Abbatangelo ${ }^{2, *(\mathbb{D})}$ and Veronica Sberveglieri ${ }^{1,2}$ (D) \\ 1 CNR-IBBR, Institute of Bioscience and Bioresources, Via Madonna del Piano, 10, \\ 50019 Sesto Fiorentino, FI, Italy; estefania.nunezcarmona@ibbr.cnr.it (E.N.-C.); \\ veronica.sberveglieri@ibbr.cnr.it (V.S.) \\ 2 Nano Sensor Systems, NASYS Spin-Off University of Brescia, Brescia, Via Camillo Brozzoni, 9, \\ 25125 Brescia, BS, Italy \\ * Correspondence: marco.abbatangelo@nasys.it
}

Citation: Núñez-Carmona, E.; Abbatangelo, M.; Sberveglieri, V. Internet of Food (IoF), Tailor-Made Metal Oxide Gas Sensors to Support Tea Supply Chain. Sensors 2021, 21, 4266. https://doi.org/10.3390/ s21134266

Academic Editor: Eduard Llobet

Received: 16 April 2021

Accepted: 17 June 2021

Published: 22 June 2021

Publisher's Note: MDPI stays neutral with regard to jurisdictional claims in published maps and institutional affiliations.

Copyright: (c) 2021 by the authors. Licensee MDPI, Basel, Switzerland. This article is an open access article distributed under the terms and conditions of the Creative Commons Attribution (CC BY) license (https:// creativecommons.org/licenses/by/ $4.0 /)$.

\begin{abstract}
Tea is the second most consumed beverage, and its aroma, determined by volatile compounds (VOCs) present in leaves or developed during the processing stages, has a great influence on the final quality. The goal of this study is to determine the volatilome of different types of tea to provide a competitive tool in terms of time and costs to recognize and enhance the quality of the product in the food chain. Analyzed samples are representative of the three major types of tea: black, green, and white. VOCs were studied in parallel with different technologies and methods: gas chromatography coupled with mass spectrometer and solid phase microextraction (SPME-GCMS) and a device called small sensor system, (S3). S3 is made up of tailor-made metal oxide gas sensors, whose operating principle is based on the variation of sensor resistance based on volatiloma exposure. The data obtained were processed through multivariate statistics, showing the full file of the pre-established aim. From the results obtained, it is understood how supportive an innovative technology can be, remotely controllable supported by machine learning (IoF), aimed in the future at increasing food safety along the entire production chain, as an early warning system for possible microbiological or chemical contamination.
\end{abstract}

Keywords: volatiloma; tea; MOX sensors; S3; GC-MS

\section{Introduction}

Tea is native to the northern hills at the foot of the Himalayas where the inhabitants chewed Camellia sinensis for medicinal purposes. The Chinese populations then invented preservation techniques to increase the shelf life and facilitate the transport of the product. Over time, the techniques have improved, and the cultivation areas have increased so as to arrive at the point today where many varieties are known [1].

It is one of the most consumed beverages worldwide, with an increase in the consumption of $23.4 \%$ in the last 7 years, reaching 297 billion liters by 2021 . Generally, tea is an aromatic beverage prepared by pouring hot or steaming water over dried or fresh leaves of the Camellia sinensis (green, white, and Oolong teas), an evergreen shrub (bush) and Camellia assamica (black and Pu-Erh tea), which originate and are cultivated, respectively, in China and India [2,3].

The most produced and consumed teas worldwide are green and black teas [4].

Tea is an infusion, but not all infusions are tea, as there are infusions or herbal teas that originate from red fruits, chamomile, mint, lavender, etc.

The tea leaves undergo different treatments that determine their classification. Spices or herbs are added to the basic tea in order to spice up the flavor and taste. The first classification is based on the fermentation treatment and is also the classification used at customs; in particular, we have:

- $\quad$ Fermented tea: black and Pu-Erh tea 
- Unfermented tea: green and white tea,

- Partially or semi-fermented tea: Oolong tea.

In addition to this classification, the teas are placed in other classes based on the following specific treatments: scented tea, flavored tea, smoked tea, blends, pressed teas, and a bouquet of tea and flowers.

There are many distinctive types of tea; some, such as Darjeeling, Ceylon, Oolong, etc., have cooling, slightly bitter, and astringent flavors, [5-8] while others have vastly different profiles that include sweet, nutty, floral, or grassy notes.

Tea leaves contain thousands of chemical compounds and release volatile compounds (VOCs), which contribute to the definition of product quality [9-14].

The aroma is one of the determining factors in the quality of tea and is due to the volatile compounds. Volatile compounds are mainly responsible for the flavor and aroma of the infusion, and many of them are not present in the fresh leaf but develop after processing.

There are more than 600 volatile compounds (VCs) in tea, resulting from the enzymatic action on odorless compounds present in the leaf that are released after rolling and fermentation [15]. The volatile aromatic compounds differ according to the types of tea, both for the "different" fresh material and for different production processes, without forgetting that the final consumer requires that the purchased product be recognized and standardized.

Recent research has shown that the volatile aromatic components of tea are influenced by several factors: cultivar, area of cultivation, cultural practices, production methods, and conservation [16-19].

Many kinds of classical analytical chemical techniques such as the gas chromatography coupled with mass spectrometry (GC-MS) have been largely used and have demonstrated their accuracy and specificity, but present important limits are normally expensive and time consuming and require appropriately trained staff to operate them.

On the other hand, an innovative tailor-made gas sensor device named small sensor systems (S3) has been applied broadly in the quality control in food the field and environmental monitoring as well exhibiting remarkable results [20-22].

This innovative device, S3, is fast, remotely controllable, totally user friendly, and, once trained, does not need any special skilled staff to operate it. In particular the S3 device is totally tailor-made for the specific application. That is, the sensors are grown, calibrated, and used on the basis of the class of VOCs on which they will be used, thus managing to obtain greater sensitivity and accuracy.

It can then be easily inserted into the production chain, for the evaluation of quality standards or to follow, for example, the evolution of the product over time.

The goal of this study is the characterization of the aroma of different types of tea and the definition of their volatiloma through the use of two different approaches, to support the supply chain of tea. Providing a portable device capable of monitoring a greater quantity of product at low costs and very quickly in a noninvasive way to facilitate compliance with quality standards.

\section{Materials and Methods}

The samples taken into consideration belong to 3 more consumed worldwide types of tea: black tea, green tea, and white tea. In this study, $20 \mathrm{~mL}$ chromatographic vials were used, each filled with approximately one sachet, $2 \pm 0.2 \mathrm{~g}$ of tea. The used sample, the code name, and the number of replicas used for each technique are represented in Table 1.

During the sampling process, no chemical extraction or thermal shock was carried out on the samples in order to keep the aroma of the dried product, to evaluate its actual characteristics. The vials were closed with aluminum caps containing polytetrafluoroethylene (PTFE) and silicone septa. The operational conditions were interpreted in Section 2.2, respectively. 
Table 1. Samples description.

\begin{tabular}{|c|c|c|c|c|c|}
\hline \multirow{2}{*}{ Kind } & \multirow{2}{*}{ Code } & \multirow{2}{*}{ Description } & \multirow{2}{*}{ Components } & \multicolumn{2}{|c|}{$\begin{array}{l}\text { Number of } \\
\text { Replicates }\end{array}$} \\
\hline & & & & GC-MS & S3 \\
\hline \multirow{4}{*}{ Green tea } & TGO & $\begin{array}{l}\text { Green tea with } \\
\text { orange aroma }\end{array}$ & $\begin{array}{c}88 \% \text { Green tea }+10 \% \\
\text { natural orange aroma }+1 \% \\
\text { loto flower }+1 \% \text { orange skin }\end{array}$ & 3 & 5 \\
\hline & SGP & Pure green tea & $100 \%$ Green tea & 3 & 12 \\
\hline & SGL & $\begin{array}{l}\text { Green tea with } \\
\text { lemon aroma }\end{array}$ & $\begin{array}{c}\text { Green tea } 83 \%+\text { lemon } \\
\text { aroma }+ \text { lemon juice } \\
\text { concentrate } 4 \%\end{array}$ & 3 & 12 \\
\hline & SGM & $\begin{array}{l}\text { Green tea with } \\
\text { Matcha tea }\end{array}$ & $\begin{array}{c}\text { Green tea + green tea } \\
\text { Matcha }\end{array}$ & 3 & 12 \\
\hline \multirow{6}{*}{ Black tea } & TBV & $\begin{array}{l}\text { Black tea with } \\
\text { vanilla aroma }\end{array}$ & $\begin{array}{c}91,5 \% \text { tea }+8 \% \text { aroma }+ \\
0,5 \% \text { vanilla }\end{array}$ & 3 & 5 \\
\hline & $\mathrm{TBC}$ & $\begin{array}{l}\text { Pure black tea from } \\
\text { Ceylon }\end{array}$ & $\begin{array}{c}\text { 100\% Black tea Ceylon Sri } \\
\text { Lanka }\end{array}$ & 3 & 12 \\
\hline & EBL & $\begin{array}{l}\text { Black tea with lemon } \\
\text { aroma }\end{array}$ & $\begin{array}{l}\text { Black tea from India and } \\
\text { lemon aroma }\end{array}$ & 3 & 12 \\
\hline & EBB & Black tea Earl Grey & $\begin{array}{c}\text { Black Tea from India + } \\
\text { bergamot juice }\end{array}$ & 3 & 12 \\
\hline & EBP & Pure black tea & Biological black Tea & 3 & 12 \\
\hline & SBL & $\begin{array}{c}\text { Black tea with lemon } \\
\text { aroma }\end{array}$ & $\begin{array}{c}\text { Black tea }+ \text { aroma }+1.04 \% \\
\text { powder of lemon juice }\end{array}$ & 3 & 12 \\
\hline White tea & BWL & $\begin{array}{l}\text { White tea with } \\
\text { lemongrass }\end{array}$ & $\begin{array}{c}\text { White tea leaf } 90 \% \text {, dried } \\
\text { lemongrass } 10 \%\end{array}$ & 3 & 8 \\
\hline \multicolumn{4}{|c|}{ Total number of samples for each technique } & 33 & 114 \\
\hline
\end{tabular}

\subsection{GC-MS Analysis Conditions}

After closure, vials were placed in the autosampler HT280T (HTA s.r.l., Brescia, Italy) to proceed with vial conditioning and volatile organic compound (VOC) extraction.

Conditioning of the sample was performed as follows: filled vials were maintained for $15 \mathrm{~min}$ at $40{ }^{\circ} \mathrm{C}$ in order to equilibrate the headspace (HS) of the sample and to remove any variables. Afterward, VOCs extraction was performed using solid-phase microextraction (SPME) analysis, and the fiber used for the adsorption of volatiles was a divinylbenzene/carboxen/polydimethylsiloxane (DVB/CAR/PDMS) 50/30 $\mu \mathrm{m}$ (Supelco Co. Bellefonte, PA, USA) placed on the HT280T autosampler. The fiber was exposed to the vial HS in the HT280T oven thermostatically regulated at $40^{\circ} \mathrm{C}$ for $15 \mathrm{~min}$.

The GC instrument used in this work was a Shimadzu GC 2010 PLUS (Kyoto, KYT, Japan), equipped with a Shimadzu single quadrupole mass spectrometer (MS) MS-QP2010 Ultra (Kyoto, KYT, Japan). Fiber desorption took place in the GC-MS injector for 6 min at $250^{\circ} \mathrm{C}$. GC was operated in the direct mode throughout the run, while the separation was performed on a MEGA-WAX capillary column, $30 \mathrm{~m} \times 0.25 \mathrm{~mm} \times 0.25 \mu \mathrm{m}$ film thickness, (Agilent Technologies, Santa Clara, CA, USA). Hydrogen was used as the carrier gas and has been produced by GENius PF500, FullTech Instruments Srl. (Rome, Italy) at a constant flow rate of $2.34 \mathrm{~mL} / \mathrm{min}$.

The GC oven temperature programming was applied as follows: at the beginning, the chromatographic column was held at $40^{\circ} \mathrm{C}$ for $2 \mathrm{~min}$ and, subsequently, the temperature was raised from 40 to $100{ }^{\circ} \mathrm{C}$ at $2{ }^{\circ} \mathrm{C} / \mathrm{min}$. Next, the temperature was raised from 100 to $180{ }^{\circ} \mathrm{C}$, with a rate of $5{ }^{\circ} \mathrm{C} / \mathrm{min}$; finally, the temperature was raised from 180 to $230^{\circ} \mathrm{C}$ at a rate of $10^{\circ} \mathrm{C} / \mathrm{min}$ and was maintained for $5 \mathrm{~min}$, for a total program time of $58 \min [21,23,24]$. 
During the analysis, the GC-MS interface was kept at $200{ }^{\circ} \mathrm{C}$, with the mass spectrometer in the electron ionization (EI) mode $(70 \mathrm{eV})$ and related to instrument tuning, and the ion source was kept at $200{ }^{\circ} \mathrm{C}$. Mass spectra were collected over 35 to $500 \mathrm{~m} / \mathrm{z}$, in a range in the total ion current (TIC) mode, with scan intervals at $0.3 \mathrm{~s}$. VOC identification was carried out using the NIST11 and the FFNSC2 libraries of mass spectra.

Chromatogram peak integration was performed using the peak area as target parameter programming an automatic integration round, using 70 as the minimum number of peak detection and 500 as the minimum area to detect. Other parameters used in the automatic peak integration were slope $100 / \mathrm{min}$, width $2 \mathrm{~s}$, drift $0 / \mathrm{min}$, and doubling time (T.DBL) $1000 \mathrm{~min}$, and no smoothing method was applied. The final round of peak integration was performed by manual peak integration for all the obtained chromatograms.

\subsection{S3 Analysis Conditions}

The chosen sensors for the application were installed on the S3 device, an acronym that stands for small sensor system.

The device that was designed and built by Nasys S.r.l. (www.nasys.it, accessed on 21 June 2021) is an innovative spin-off born in the University of Brescia, where tailor-made sensors were produced.

S3 is composed of three essential parts: (A) sensors chamber, (B) fluid dynamic circuit for the distribution of volatile compounds, and $(C)$ electronics control system.

(A) The sensors are housed inside a steel chamber isolated from the external environment, except for an inlet and an outlet path for the passage of volatile compounds. In addition to the MOX sensors, a temperature, humidity sensor, and a flow sensor are also allocated as necessary to take into account the number of variables during the analysis. The dimensions of the chamber are $11 \times 6.5 \times 1.3 \mathrm{~cm}$.

On the 11 and $6.5 \mathrm{~cm}$ sides, 6 and 5 positions have been obtained, respectively: 10 positions were available for the use of metal oxide (MOX) sensors and one for the temperature and humidity sensor. The list of MOX used in this study is represented in Table 2, where the technology of production, RGTO (rheotaxial growth and thermal oxidation) or nanowire, the sensing material $\left(\mathrm{SnO}_{2}\right.$ or $\left.\mathrm{CuO}\right)$, and the working temperature are indicated.

Table 2. Sensor array composition of S3 device and sensors characteristics.

\begin{tabular}{clc}
\hline Material & Kind & Working Temperature \\
\hline $\mathrm{SnO}_{2}+\mathrm{Au}$ & $\mathrm{RGTO}$ & $400{ }^{\circ} \mathrm{C}$ \\
$\mathrm{SnO}_{2}$ & $\mathrm{RGTO}$ & $400^{\circ} \mathrm{C}$ \\
$\mathrm{CuO}$ & Nanowire & $350{ }^{\circ} \mathrm{C}$ \\
$\mathrm{SnO}_{2}+\mathrm{Au}$ & Nanowire & $350{ }^{\circ} \mathrm{C}$ \\
$\mathrm{SnO}_{2}$ & Nanowire & $350^{\circ} \mathrm{C}$ \\
\hline
\end{tabular}

(B) The fluid dynamic circuit consists of a pump (Knf, model: NMP05B), polyurethane pipes, a solenoid valve, and a metal cylinder containing activated carbon for filtering possible interfering odors present in the environment. The pump flow is regulated by a needle valve placed at the chamber inlet; the flow range for tea analysis was set to $100 \mathrm{sccm}$.

(C) The electronic boards make it possible to acquire the resistances of the sensors, the correct heating of the sensors themselves to their operating temperature, and the sending of data to the Web App dedicated to the S3 device through an internet connection. In addition, it allows communication and synchronization with an autosampler. This is an autosampler of the company HTA S.r.l. (model HT2010H) which allows one to prepare batches of 42 samples per measurement session. Tea samples were conditioned for $5 \mathrm{~min}$ at $40^{\circ} \mathrm{C}$ with $1 \mathrm{~min}$ in a shaking mode in order to equilibrate the headspace (HS). 
The RGTO technique requires two phases of deposition: the first step is the metallic thin film by DC magnetron sputtering from a metallic target to a substrate at higher temperatures than the melting point of the metal; and the second step is the thermal oxidation period in order to produce a metal oxide coating with stable stoichiometry [25]. The surface of the thin film is rough, and this is desirable since it has a high surface-tovolume ratio and reactivity to the gaseous species [26]. In addition, the presence of this very rough surface morphology, also known as 'spongy agglomerates', gives rise to a highly specific area required for high-sensitivity gas sensors [27]. Nanowires display extraordinary crystalline quality and a very high length-to-width ratio, resulting in improved sensitivity and long-term material stability for extended operation [28,29]. The fabrication method consists of the evaporation of the powder (metal oxide) at high temperatures in a controlled atmosphere at pressures of less than a hundred mbar (50-200 mbar) and the subsequent mass transfer of the vapor (50-100 sccm) to substrates held at lower temperatures in relation to the evaporation source area. This growth technique is called a vapor-liquid-solid (VLS) mechanism.

For $\mathrm{SnO}_{2}$ sensors, the powders are mounted in the middle of the furnace at $1370{ }^{\circ} \mathrm{C}$, and the inert air flow at temperatures between 350 and $400{ }^{\circ} \mathrm{C}$ is used as a carrier from the furnace to the substrate where nanowires begin to develop [30].

S3 was previously used, with considerable success, in numerous studies applied to the field of food technology and quality control [31,32]. The output of the S3 analysis consists of the sensors' resistance variation due to the interaction of VOCs with the sensing elements. The exposure to VOCs lasted $1 \mathrm{~min}$, while $9 \mathrm{~min}$ passed to restore sensors' baseline. Prior to analysis, the sensors' responses in terms of resistance $(\Omega)$ were standardized relative to the first value of the acquisition (R0). This standardization was performed for each measure so that for all the sensors, the first point value was 1 , smoothing differences in the starting value of resistances between the measures themselves. For all the sensors, the difference between the first value and the minimum value was determined during the time of analysis; thus, the value $\Delta R / R 0$ was derived. These features were used as input for principal component analysis (PCA). Here, PCA has been used to visualize the data cluster. By contrast, a hard approach to quantify the accuracy of the system was employed. In particular, the k-nearest neighbor (k-NN) algorithm was used with 5-fold crossvalidation technique. The aim of crossvalidation is to test the model's ability to predict new data that were not used in estimating it, in order to counteract overfitting or selection bias. The accuracy provided is the mean of the accuracies of the 5 steps of prediction.

\section{Results}

\subsection{GC-MS Results}

After closure, vials were placed in the autosampler HT280T (HTA s.r.l., Brescia, Italy) to proceed with vial conditioning and volatile organic compound (VOC) extraction.

Regarding the data extracted from the GC-MS-SPME analysis, the volatile fingerprints for each tea were identified, and the tables are presented at the end of the article in Appendix A (Tables A1-A11). It was possible to identify the common compounds between the green tea samples that are presented in Table 3. 
Table 3. Common compounds between the analyzed green teas.

\begin{tabular}{ccccc}
\hline Compound & TGO & SPG & SGL & SGM \\
\hline Cyanoacetic acid & $1.685 \times 10^{5}$ & $1.165 \times 10^{5}$ & $5.677 \times 10^{4}$ & $6.301 \times 10^{4}$ \\
Hexanal & $7.22 \times 10^{5}$ & $5.751 \times 10^{5}$ & $2.889 \times 10^{4}$ & $3.529 \times 10^{5}$ \\
Limonene & $1.378 \times 10^{7}$ & $1.976 \times 10^{5}$ & $2.602 \times 10^{8}$ & $2.011 \times 10^{5}$ \\
6-metile 5-epten-2-one & $6.233 \times 10^{5}$ & $3.789 \times 10^{5}$ & $2.731 \times 10^{5}$ & $3.617 \times 10^{5}$ \\
Nonanal & $5.81 \times 10^{5}$ & $1.133 \times 10^{5}$ & $9.298 \times 10^{4}$ & $1.462 \times 10^{5}$ \\
$\alpha$-terpineol & $1.098 \times 10^{6}$ & $3.145 \times 10^{6}$ & $8.024 \times 10^{6}$ & $7.628 \times 10^{5}$ \\
5,6,7,7a-tetrahydro, & & & & \\
4,4,7a- Trimethyl 2 & $3.448 \times 10^{5}$ & $4.843 \times 10^{5}$ & $4.819 \times 10^{5}$ & $2.836 \times 10^{5}$ \\
$(4 \mathrm{H})$-benzofuranone & & & & \\
\hline
\end{tabular}

In total, an average of 100 volatile compounds were found for each sample analyzed, of which only seven in common to all samples.

- Cyanoacetic acid: $\left(\mathrm{C}_{3} \mathrm{H}_{3} \mathrm{NO}_{2}\right)$ is an organic compound that has two functional groups: $\mathrm{COOH}$ typical of carboxylic acids and $\mathrm{NC}$ with triple bond typical of nitriles. It is obtained from the treatment of chloroacetate with sodium cyanide followed by acidification or electrolysis by cathodic reduction of carbon dioxide or the anodic oxidation of acetonitrile. It is a precursor of synthetic caffeine by theophylline [33].

- Hexanal: $\left(\mathrm{C}_{6} \mathrm{H}_{10} \mathrm{O}\right)$ is an aldehyde. In the cell, it is contained in the cytoplasm. It has a sweet almond and honey flavor and is found in several foods including soy, cucumber, black elderberry, and black currant [33].

- Limonene: $\left(\mathrm{C}_{10} \mathrm{H}_{16}\right)$ is the most widespread and most important monoterpene. It has a lemon smell and turpentine-like notes. It is obtained by steam distillation of citrus peel and pulp obtained from the production of juice [33]. It should be specified that it is present as two isomers: R-LIMONENE and D-LIMONENE. In particular, it is R-LIMONENE in the SGP, while in the others, it is D-LIMONENE, and both isomers are present in the SGM.

- 6-methyl, 5-hepten-2-one: $\left(\mathrm{C}_{8} \mathrm{H}_{14} \mathrm{O}\right)$ is an unsaturated ketone called sulcatone. It has a strong, greasy, green, citrus smell and tastes reminiscent of pear. It is obtained from citronella or citral oil by mixing for $12 \mathrm{~h}$ in aqueous solution with $\mathrm{K} 2 \mathrm{CO} 3$ and subsequent distillation and fractionation under vacuum. It was originally identified in lemongrass; later, it was also discovered in the essential oils of lemons and geraniums. We also find this ketone in grapes, melon, peaches, avocados, cognac, mangoes, rice, olives, blueberries, and more [33].

- Nonanal: $\left(\mathrm{C}_{9} \mathrm{H}_{18} \mathrm{O}\right)$ is an aldehyde. It has a strong and greasy odor which develops notes of orange and rose when diluted. The fat recalls the flavor of citrus fruits. It is synthesized by the catalytic oxidation of the corresponding alcohol or by the reduction of the respective acid. In nature, we find it in orange, mandarin, lemon, and lime oils. It is also found in more than 200 foods and beverages including apples, tomatoes, rum, wine, plum, coconut, cardamom, avocado, corn oil, broccoli, milk, eggs, tea, and others [34].

- $\quad \alpha$-Terpineol: $\left(\mathrm{C}_{10} \mathrm{H}_{18} \mathrm{O}\right)$ is a monoterpenic alcohol. It has a characteristic smell of lilac with a sweet flavor reminiscent of peach. It is obtained from the hydration of the terpene or from the pentane tricarboxylic acid by cyclization or from the isoprene and methyl-vinyl-ketone. It is present in more than 150 derivatives of herbs, leaves, and flowers. Form D is found in cardamom, star anise, sage, and marjoram oil. The $\mathrm{L}$ form is present in lavender, lime, and cinnamon leaves. The racemic form is the eucalyptus [33,34].

- 5,6,7,7a-Tetrahydro, 4,4,7a-Trimethyl-2(4H)-benzofuranone: $\left(\mathrm{C}_{11} \mathrm{H}_{16} \mathrm{O}_{2}\right)$ is a heterocyclic compound. It has a coumarin and musky smell. This compound is formed from the photo-oxidation of carotene. The flavor is linked to the fruit and in particular to their point of ripeness. It is obtained from the degradation process of $\beta$-carotene in 
the presence of nitrogen and air. It occurs naturally in lemongrass and sweet grass oil [33].

On the other hand and regarding the GC-MS results from the black tea samples, it is possible to say that there were seven black teas subjected to GC-MS analysis, with different flavors and belonging to different origins and composition. The results obtained showed that there are four VOCs in common to all the samples (Table 4).

Table 4. Common compounds between the analyzed black teas.

\begin{tabular}{ccccccc}
\hline Compound & TBV & EBP & EBL & EBB & SBL & TBC \\
\hline Nonanal & $3.739 \times 10^{5}$ & $6.164 \times 10^{4}$ & $2.278 \times 10^{5}$ & $1.129 \times 10^{5}$ & $1.041 \times 10^{5}$ & $1.198 \times 10^{5}$ \\
Ammonium acetate & $2.141 \times 10^{6}$ & $4.641 \times 10^{4}$ & $5.945 \times 10^{5}$ & $6.868 \times 10^{5}$ & $2.162 \times 10^{5}$ & $1.023 \times 10^{5}$ \\
Phenylethyl alcohol & $8.167 \times 10^{4}$ & $4.682 \times 10^{4}$ & $4.243 \times 10^{4}$ & $7.557 \times 10^{4}$ & $6.461 \times 10^{4}$ & $5.550 \times 10^{4}$ \\
$5,6,7,7$ a-tetrahydro, 4,4,7a- & & & & & \\
Trimethyl 2 & $2.784 \times 10^{5}$ & $3.536 \times 10^{4}$ & $1.473 \times 10^{5}$ & $7.543 \times 10^{4}$ & $1.073 \times 10^{5}$ & $1.053 \times 10^{5}$ \\
$(4 \mathrm{H})$-benzofuranone & & & & & \\
\hline
\end{tabular}

- Nonanal: $\left(\mathrm{C}_{9} \mathrm{H}_{18} \mathrm{O}\right)$ is an aldehyde. It has a strong and greasy odor which develops notes of orange and rose when diluted. The fat recalls the flavor of citrus fruits. It is synthesized by the catalytic oxidation of the corresponding alcohol or by the reduction of the respective acid. In nature, we find it in orange, mandarin, lemon, and lime oils. It is also found in more than 200 foods and drinks including apples, tomatoes, rum, wine, plum, coconut, cardamom, avocado, corn oil, broccoli, milk, egg, tea, and others [34].

- Ammonium acetate: $\left(\mathrm{C}_{2} \mathrm{H}_{7} \mathrm{NO}_{2}\right)$ is an ammonium salt obtained from the reaction between ammonia and acetic acid. It is used to regulate acidity in food, even though the EU decided to ban its use as a food additive [33].

- Phenylethyl alcohol: $\left(\mathrm{C}_{8} \mathrm{H}_{10} \mathrm{O}\right)$ is an alcohol. It has a characteristic rose odor and initially a slight bitter taste. The dessert is reminiscent of peaches. It is synthesized from toluene, benzene, or styrene. It is found in esterified form in rose concentrate or distilled rose water. It is present in the essential oil of lily, narcissus, and tea leaves but not only because it has been found in more than 200 foods and drinks including peaches, grapes, coffee, tea, mushrooms, mango, kiwi, rum, whiskey, milk, butter, cheese, and more [33,34].

- 5,6,7,7a-Tetrahydro, 4,4,7a- trimethyl $2(4 \mathrm{H})$-benzofuranone: $\left(\mathrm{C}_{11} \mathrm{H}_{16} \mathrm{O}_{2}\right)$ is a heterocyclic compound. It has a coumarin and musky smell. This compound is formed from the photo-oxidation of carotene. The flavor is linked to the fruit and in particular to their point of ripeness. It is obtained from the degradation process of $\beta$-carotene in the presence of nitrogen and air. It occurs naturally in lemongrass and sweet grass oil [33].

\subsection{S3 Results}

For each analyzed tea type (black and green), a specific matrix was created as shown in the respective PCA scores plot. Conversely, the dataset used in the first PCA was obtained by joining the three tea types considered in an initial test to check the performances of the system. In Figure 1, the results obtained from the comparative analysis of the S3 for the samples belonging to the three types of teas BWL (white), TGO (green), and TBV (black) are represented. 


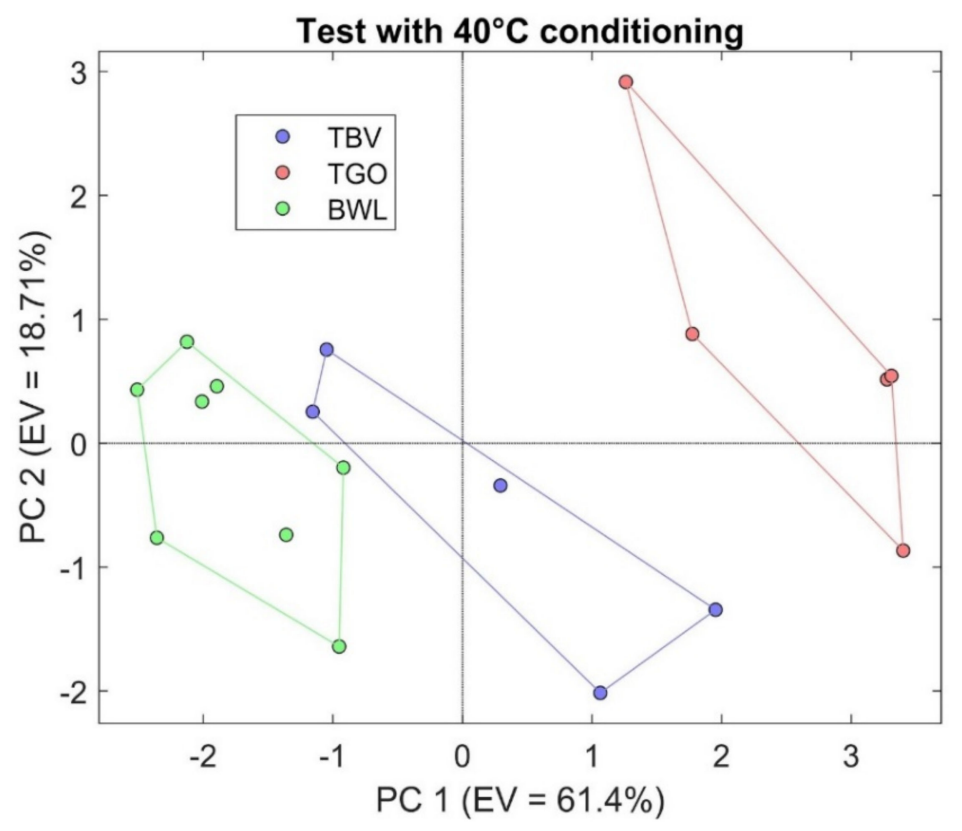

Figure 1. PCA analysis representing the results obtained from the comparison between black, green, and white tea.

Total explained variance reached a value of $80.11 \%$, exhibiting a good cluster separation between the three different categories of teas. On the other hand, further exploration of the data was conducted proceeding the comparison of different green and black teas in order to explore the capacity of the instrument to distinguish the same type of tea (black or green) but with different treatments and/or aromatization. In Figure 2, the results of the analysis of SGP, SGL, and SMG for one RGTO sensor as the normalized resistance as a function of time (left) are represented; these results are more evident in the bar chart where the line on the bars is the indicated standard deviation of the mean (Figure 2b).

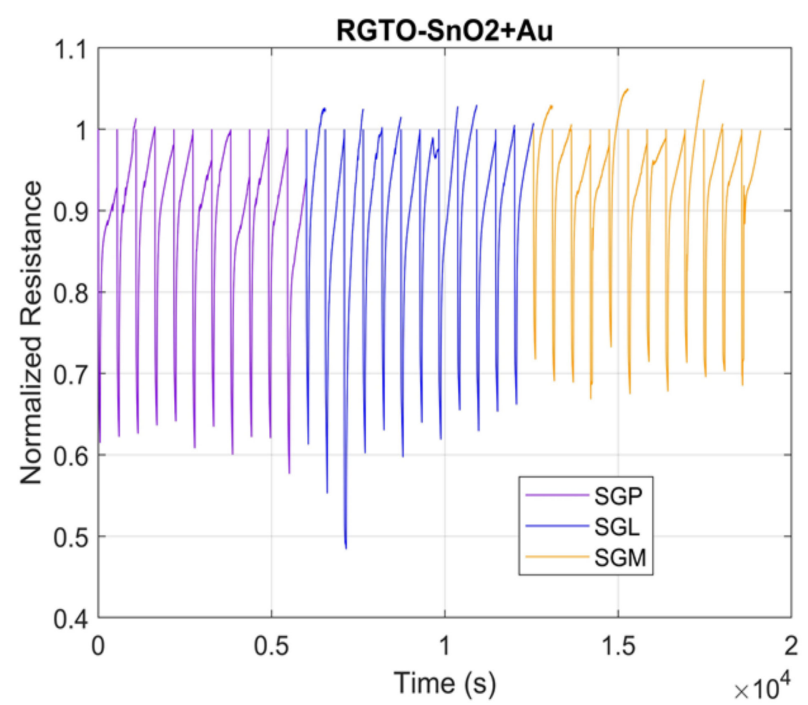

(a)

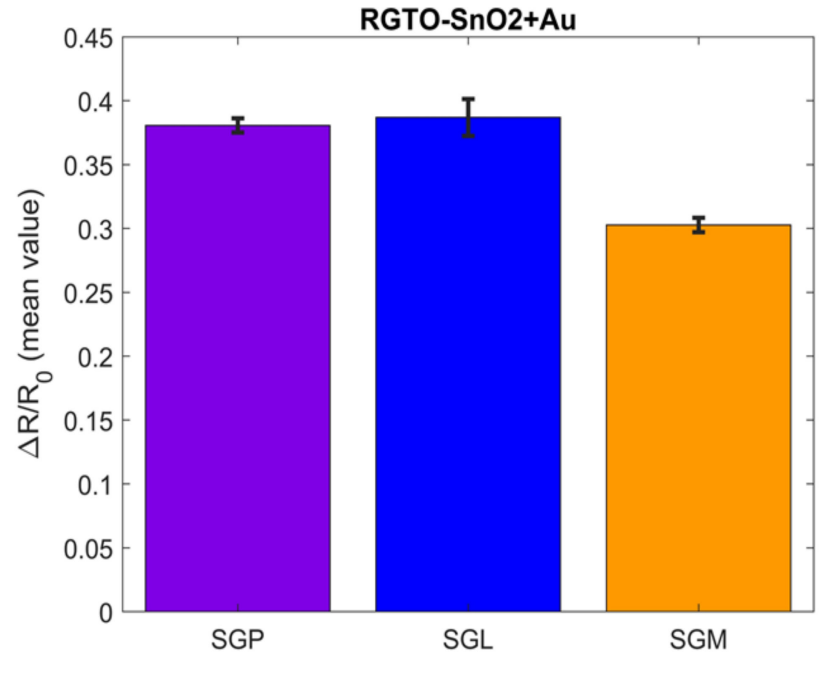

(b)

Figure 2. (a) Sensor response representation to the green teas $\mathrm{RGTO}$ sensor $\mathrm{SnO}_{2}+\mathrm{Au}$ and (b) mean values for the $\Delta \mathrm{R} / \mathrm{R} 0$ with the representation of the SD bar for the different green teas measurements.

Regarding the result obtained, applying multivariate analysis to the signals obtained from all the sensors when measuring the types of green tea is represented in Figure 3. 


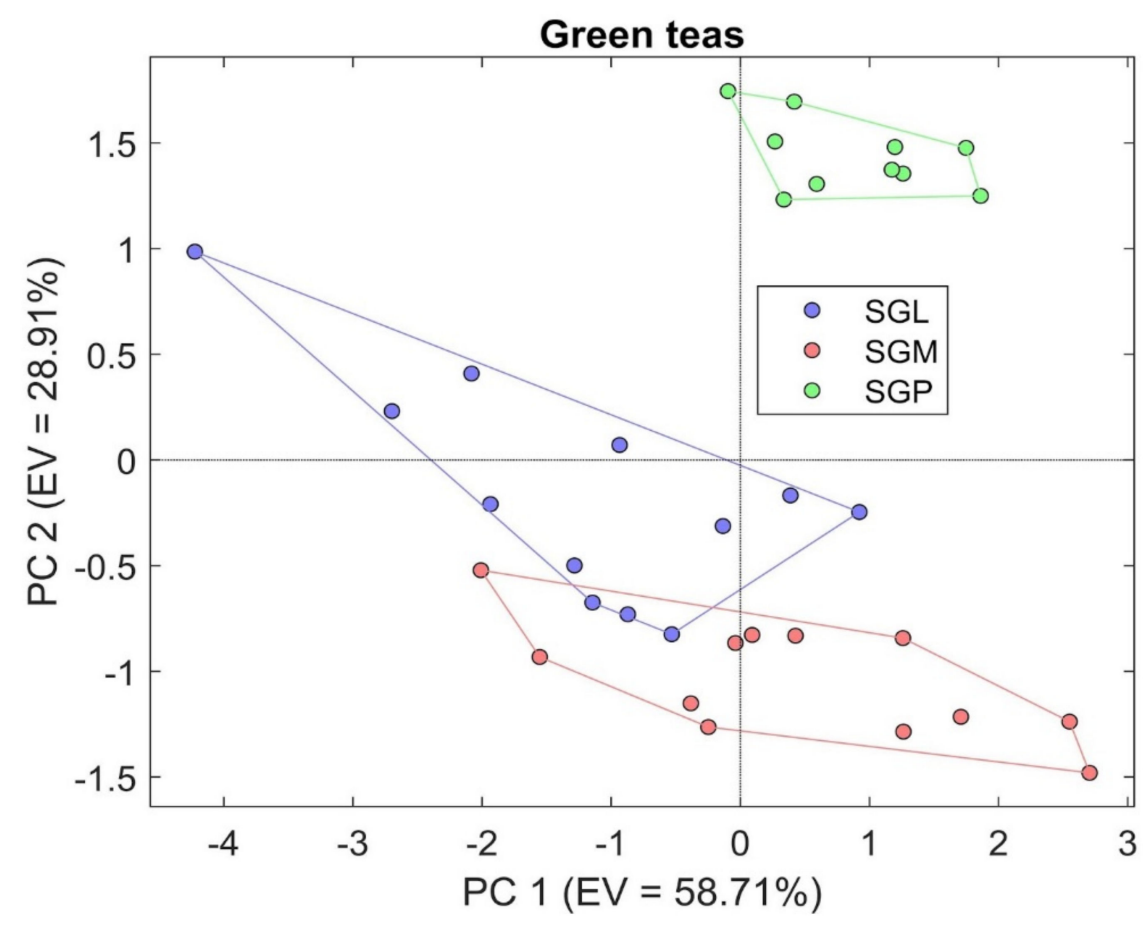

Figure 3. PCA analysis representing the results obtained from the comparison between green tea.

The result obtained is very satisfactory, because considering the two main components, the total explained variance enclosed in the graph reaches $87.82 \%$. The mean accuracy achieved with $\mathrm{k}-\mathrm{NN}(\mathrm{k}=5)$ was equal to $88.57 \%$.

Regarding the black teas, the samples that were taken into consideration were EBP, EBL, EBB, SBL, and TBC. Figure $4 \mathrm{a}$, b clearly shows the different responses of a $\mathrm{SnO}_{2} \mathrm{RGTO}$ sensor to the various black tea samples.

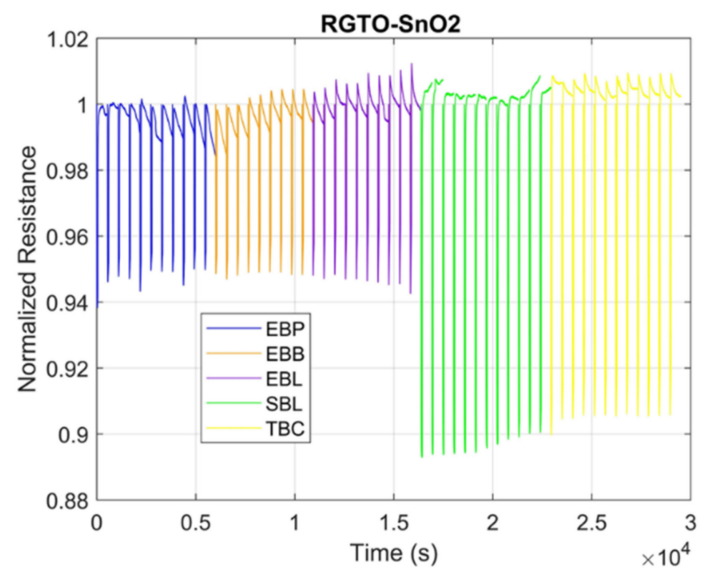

(a)

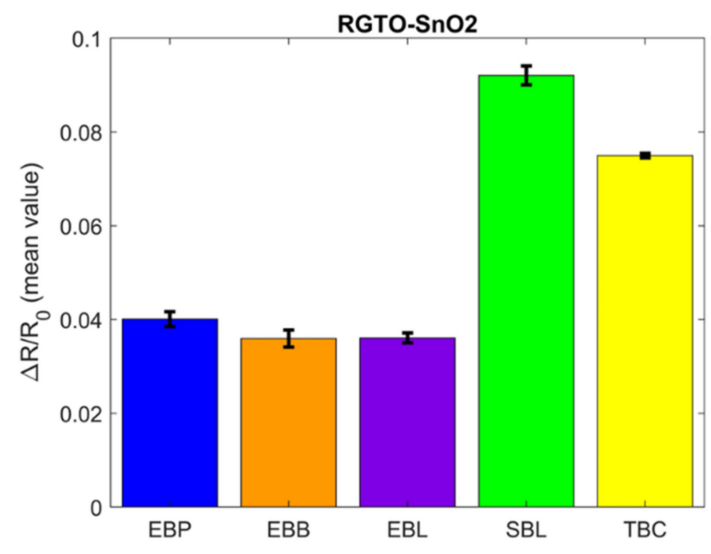

(b)

Figure 4. (a) Sensor response representation to the green teas $\mathrm{RGTO}$ sensor $\mathrm{SnO}_{2}$ and (b) mean values for the $\Delta \mathrm{R} / \mathrm{R} 0$ with the representation of the SD bar for the different green teas measurements.

As before, PCA was then applied, and the results can be seen in Figure 5. The expected results were confirmed using PCA analysis, obtaining a good cluster separation, apart from the EBL, EBB, and EBP. The mean accuracy achieved with $k-N N(k=5)$ was equal to $83.45 \%$. 


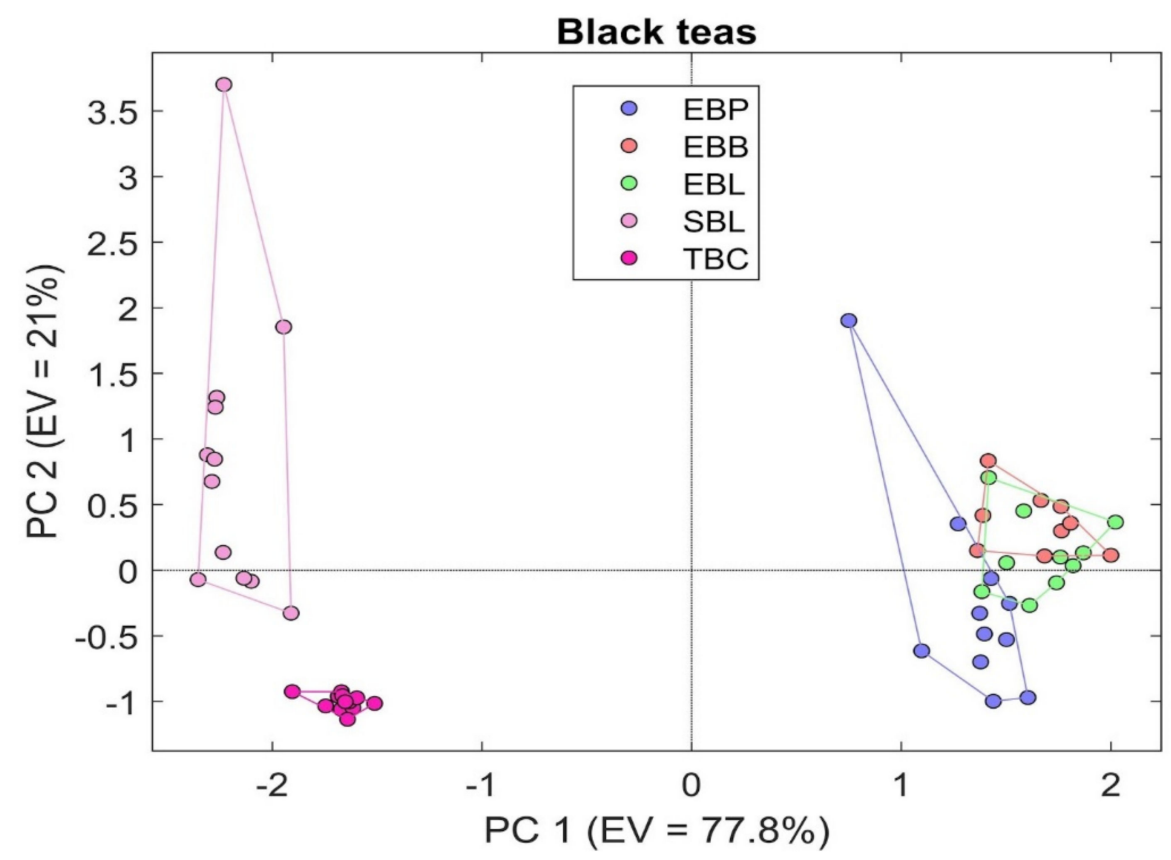

Figure 5. PCA analysis representing the results obtained from the comparison between black tea.

\section{Discussion}

Regarding the GC-MS results from the treated green teas, an average of 100 volatile compounds were found for each sample analyzed, of which only seven in common to all samples (Table 3). As can be seen from the description, all are naturally occurring compounds in various foods and drinks, especially fruit and vegetables, except for cyanoacetic acid which is a precursor of synthetic caffeine. Volatile compounds give the tea floral, fruity, vegetable, spicy, and aromatic notes. On the other hand, regarding the GC-MS results from the black tea samples, seven teas were subjected to GC-MS analysis, with different characteristics. The results obtained showed that there were four VOCs in common to all the samples (Table 4). In general, EBP, SBL, and TBC were present in more than $100 \mathrm{VOCs}$, but in the others, about 90 have been found. The few compounds common to black teas can be explained by vanilla flavored black tea (TBV), which has fewer compounds in common with the other samples.

The four citrus-flavored samples (TBL, EBB, EBL, and SBL) have five compounds in common over the previous four: $\beta$-myrcene, D-limonene, Benzaldehyde, $\alpha$-terpineol, and Carvone, which are present in citrus fruits both in essential oils and in peels. In TBV, there is a maximum peak in the direction of vanillin, which is the aromatic aldehyde that gives the vanilla aroma, which records an abundance of $8.287 \times 10^{6}$. In general, even in black teas, as already found in green teas, volatile compounds are present in nature and impart aromas that have floral, vegetable, spicy, fruity, and aromatic notes.

Nonetheless, the results obtained throughout the use of the sensor device show a good rate of identification for the teas, since more than the $80 \%$ of the explained variance was enclosed between PC1 and PC2, and good clustering capacity can be seen in Figure 2.

Taking into consideration the response of one of the RGTO sensors for the green teas' analysis, in particular SGP, SGL, and SMG, it is evident, in the graphs of the normalized resistance as a function of time (Figure 2a), how the samples are well separated according to the different aromatization, even if some have similar values. In fact, as can be seen in Figure $2 \mathrm{a}$, the violet and blue values are more similar to each other. It looks even better in bar charts where the line on the bars is the indicated standard deviation of the mean, highlighting its reproducibility (Figure 2b).

On Figure 3, the results of the PCA analysis performed on green teas measurements is shown, and it is evident the separation between the green tea samples, in particular SGP, is far from SGL and SGM. This result is important not only because the instrument is able to 
recognize the aromatization tea from the pure one, separating the 2 different ones which actually slightly overlap. The result obtained is very satisfactory, because considering the two main components, the total explained variance enclosed in the graph reaches $87.82 \%$.

On the other hand, EBP, EBL, EBB, SBL, and TBC samples were taken into consideration for the analysis of the sensors' response. Figure $4 \mathrm{a}, \mathrm{b}$ clearly shows the different responses of a SnO2 RGTO sensor to the various black tea samples. This aspect is even more evident in the bar graphs (Figure $4 b$ ). It can be observed that the samples of EBP, EBB, and EBL, all of the same brand, have a variation that is very similar to each other, while the other two (SBL and TBC) have a very different variation from the first three and are also quite different between themselves. In this case, two samples of black tea aromatized with lemon were taken into consideration but of different brands, and as can be seen in the figures, the two are very different from each other, as the variation associated with SLB tea is much greater than that of ELB tea.

PCA analysis multivariate analysis for black teas (Figure 5) confirms the previous discussed data, obtaining a good cluster separation, apart from the EBL, EBB, and EBP. These last three samples belong to the same brand and have been reported previously from the sensor response to have a lower sensor response than the other two samples of black tea and consequently are all close and partly overlapping each other, in particular EBB and EBL. This last consideration can be explained by observing the chromatograms where it can be seen how EBB and EBL are mainly characterized by limonene and linalyl acetate, while in EBP, the spectrum has a net peak in correspondence with linalyl acetate and has in general a chromatogram that appears to be richer than the previous two. In this case, the explained variability enclosed by the main components greater than the one obtained for the green teas, in fact, is $98.8 \%$, and also in this case, the greatest variation explained is always along the PC1.

\section{Conclusions}

The work was based on the analysis of 11 different samples of green, black, and white tea. By applying the two techniques GC-MS and S3, the complete determination of the aromatic profile of the teas was achieved, evaluating and highlighting the similarities and differences between them so as to arrive at a discrimination based on the VOCs profile. Nearly, 100 different volatiles were identified by the mean in each tea sample. The GC-MS requires a longer and, in some ways, more elaborate analysis, while S3 allows one to obtain the result in a shorter time and more easily and user-friendly way. It can be concluded that an innovative technology such as S3 has the potential to be used from farm to fork, in food companies and in the production chain, so as to report anomalous products and prevent them from reaching the market or in any case arriving at a final product that must be excluded because it is not safe. In fact, once the anomaly is reported, it would be possible to implement a correction or exclusion of the batch from the distribution chain. It should also be emphasized that the use of this sensor technology once trained would have a positive economic impact for the production business, is also easy to use, and, thanks to the connection to the network, allows for remote data processing. In a shortterm future, this technology could be applied in industrial reality, so that food safety and the producer can benefit from it. This kind of technology could be also implemented in household environments, to control not only the dried product but also the final stage of the beverage. In fact, its use is not limited only to tea but can concern any foodstuff, as already demonstrated in other studies.

Author Contributions: Conceptualization, E.N.-C., M.A. and V.S.; methodology, E.N.-C., M.A. and V.S.; software, E.N.-C., M.A. and V.S.; validation, M.A. and V.S.; formal analysis, E.N.-C., M.A. and V.S.; investigation, E.N.-C., M.A. and V.S.; resources, V.S.; data curation, M.A., E.N.-C. and V.S.; writing-original draft preparation, E.N.-C., M.A. and V.S.; writing-review and editing, E.N.-C., M.A.; visualization, E.N.-C., M.A. and V.S.; supervision, V.S. All authors have read and agreed to the published version of the manuscript. 
Funding: This research received no external funding.

Institutional Review Board Statement: Not applicable.

Informed Consent Statement: Not applicable.

Data Availability Statement: Data available on request due to restrictions e.g., privacy or ethical.

Conflicts of Interest: The authors declare no conflict of interest.

\section{Appendix A}

In Appendix A, the data are presented that were extracted from the GC-MS-SPME analysis of the volatile fingerprints for each tea that have been analyzed in this work (Tables A1-A11).

Table A1. Results for the TGO sample fingerprint determination with indication of the retention time (RT) and abundance mean for every identified compound.

\begin{tabular}{|c|c|c|}
\hline RT & Compound Name & Abundance Mean \\
\hline 0.745 & Acetic acid, cyano- & 168,502 \\
\hline 0.830 & 2-Amino-4-dimethylaminomethylenepentanedinitrile & 108,883 \\
\hline 1.054 & Ethane-1,2-diimine, $\mathrm{N}, \mathrm{N}^{\prime}$-diamino- & 109,436 \\
\hline 1.065 & Acetone & 114,706 \\
\hline 2.575 & Butanoic acid, ethyl ester & $3,839,625.5$ \\
\hline 3.264 & Hexanal & 722,081 \\
\hline 4.235 & 9-Tetradecen-1-ol, acetate, (E)- & 256,238 \\
\hline 5.942 & D-Limonene & $13,781,429.5$ \\
\hline 6.678 & 2-Hexenal & 213,594 \\
\hline 6.993 & 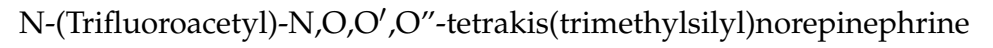 & 377,968 \\
\hline 7.628 & (+)-3-Carene, 10-(acetylmethyl)- & 259,938 \\
\hline 7.630 & 3(10)-Caren-4-ol, acetoacetic acid ester & 498,827 \\
\hline 8.286 & 1-Pentanol & 208,402 \\
\hline 8.518 & Nonane, 5-(2-methylpropyl)- & 239,091 \\
\hline 9.647 & Octanal & $165,442.5$ \\
\hline 10.755 & 3-Ethyl-3-methylheptane & 114,704 \\
\hline 10.976 & 2-Heptenal, (Z)- & $207,932.5$ \\
\hline 11.957 & 5-Hepten-2-one, 6-methyl- & 623,348 \\
\hline 14.761 & Nonanal & $581,017.5$ \\
\hline 15.175 & Oxirane, [(tetradecyloxy)methyl]- & 193,068 \\
\hline 15.666 & Oxalic acid, propyl undecyl ester & 165,284 \\
\hline 16.277 & 2-Undecenal, E- & 121,169 \\
\hline 16.306 & Oxirane, $2,2^{\prime}-(1,4$-butanediyl)bis- & 119,155 \\
\hline 17.193 & 2-Furanmethanol, 5-ethenyltetrahydro-.alpha.,.alpha.,5-trimethyl-, cis- & $1,799,498$ \\
\hline 17.647 & Undecanol-4 & 291,287 \\
\hline 17.678 & 3-Octanol, 3,6-dimethyl- & 239,713 \\
\hline 18.343 & Ammonium acetate & $1,079,115.5$ \\
\hline 18.768 & 2-Furanmethanol, 5-ethenyltetrahydro-.alpha.,.alpha.,5-trimethyl-, cis- & $2,039,755$ \\
\hline 19.085 & Octadecane, 1-chloro- & 603,170 \\
\hline 19.587 & Acetic acid, hexyl ester & 601,861 \\
\hline 19.760 & 1,6-Heptadiene, 3,5-dimethyl- & 80,227 \\
\hline 20.519 & Decanal & 622,713 \\
\hline 21.134 & Benzaldehyde & 94,325 \\
\hline 22.424 & 3-Cyclohexene-1-ethanol, .beta.,4-dimethyl- & 131,133 \\
\hline 22.431 & 1-Cyclohexene-1-methanol, 4-(1-methylethenyl)- & 140,779 \\
\hline 22.670 & 3-Heptyne-2,6-dione, 5-methyl-5-(1-methylethyl)- & 134,078 \\
\hline 22.801 & Cyclobutane, 1,2-bis(1-methylethenyl)-, trans- & 214,018 \\
\hline 22.816 & 1-Isopropenyl-3-propenylcyclopentane & 189,887 \\
\hline 23.354 & Cyclohexanol, 2,2,6,6-tetramethyl- & $1,107,971$ \\
\hline 23.360 & Citronellyl butyrate & $1,018,024$ \\
\hline 24.182 & 1,6-Octadien-3-ol, 3,7-dimethyl-, 2-aminobenzoate & $6,824,657.5$ \\
\hline
\end{tabular}


Table A1. Cont.

\begin{tabular}{|c|c|c|}
\hline RT & Compound Name & Abundance Mean \\
\hline 24.495 & 1-Octanol & $905,951.5$ \\
\hline 24.911 & Cyclohexane, 1-ethenyl-1-methyl-2,4-bis(1-methylethenyl)-, [1S-(1.alpha.,2.beta.,4.beta.)]- & $122,847.5$ \\
\hline 25.385 & 1,1-Dimethyl-4-methylenecyclohexane & 277,392 \\
\hline 25.417 & Cyclohexanone, 2-methyl-5-(1-methylethenyl)-, trans- & 243,765 \\
\hline 27.500 & Hotrienol & 80,758 \\
\hline 27.795 & Carveol & 545,775 \\
\hline 27.797 & Dispiro[2 .1.2.4] undecane, 8-methylene- & 617,343 \\
\hline 28.060 & Acetophenone & 82,331 \\
\hline 28.301 & Hexanoic acid, 6-bromo- & 217,313 \\
\hline 29.001 & 2-Cyclohexen-1-one, 2-methyl-5-(1-methylethyl)-, (S)- & $532,374.5$ \\
\hline 30.125 & Carveol & 474,827 \\
\hline 30.130 & 6-Isopropenyl-3-methoxymethoxy-3-methyl-cyclohexene & 465,247 \\
\hline 30.242 & 1-Nonanol & $768,727.5$ \\
\hline 30.972 & cis-p-Mentha-2,8-dien-1-ol & 560,885 \\
\hline 30.974 & trans-p-mentha-1(7),8-dien-2-ol & 662,768 \\
\hline 31.523 & .alpha.-Terpineol & $1,098,969$ \\
\hline 32.232 & (-)-Carvone & $3,383,059$ \\
\hline 32.611 & Undecane, 2-methyl- & 74,437 \\
\hline 32.624 & Pentadecane & 155,418 \\
\hline 33.721 & 2H-Pyran-3-ol, 6-ethenyltetrahydro-2,2,6-trimethyl- & 203,784 \\
\hline 33.982 & Carveol & 450,597 \\
\hline 34.200 & Ethanone, 1-(3-methylphenyl)- & 150,098 \\
\hline 34.340 & 1-Cyclohexene-1-carboxaldehyde, 4-(1-methylethenyl)- & 262,883 \\
\hline 34.627 & Decane, $1,1^{\prime}$-oxybis- & 92,683 \\
\hline 35.010 & 2H-Pyran-3-ol, 6-ethenyltetrahydro-2,2,6-trimethyl- & 109,855 \\
\hline 35.173 & Cyclopropane, octyl- & 181,727 \\
\hline 35.176 & Decane, 3-chloro- & 131,903 \\
\hline 35.319 & 6-Octen-1-ol, 3,7-dimethyl-, (R)- & 158,561 \\
\hline 35.332 & Citronellal & 169,686 \\
\hline 35.896 & p-Mentha-1(7),8-dien-2-ol & 152,465 \\
\hline 36.474 & 2-Cyclohexen-1-one, 3-methyl-6-(1-methylethenyl)-, (S)- & 98,294 \\
\hline 36.694 & 3-hydroxy-2-methyl-5-(prop-1-en-2-yl)cyclohexanone & 250,595 \\
\hline 37.280 & 2-Cyclohexen-1-ol, 2-methyl-5-(1-methylethenyl)-, acetate, (1R-cis)- & $1,127,661$ \\
\hline 37.837 & Heptanoic acid & $1,468,435.5$ \\
\hline 38.200 & trans-p-mentha-1(7),8-dien-2-ol & 380,766 \\
\hline 38.414 & Benzyl-diseryl phosphate & $162,123.5$ \\
\hline 38.840 & (2R,4R)-p-Mentha-[1(7),8]-diene, 2-hydroperoxide & 97,386 \\
\hline 40.616 & (-)-trans-Myrtanyl acatate & 105,666 \\
\hline 40.623 & Myrcenylacetat & 146,060 \\
\hline 40.857 & Cyclododeca-5,9-dien-1-ol, 2-methyl-, (Z,Z)- & 317,443 \\
\hline 40.859 & (2R)-Bornane-10,2-sultam & 219,341 \\
\hline 41.850 & Benzaldehyde, 4-methoxy- & 233,353 \\
\hline 43.263 & Octanoic acid & 191,580 \\
\hline 43.436 & $\begin{array}{l}\text { Cyclohexanemethanol, 4-ethenyl-.alpha.,.alpha.,4-trimethyl-3-(1-methylethenyl)-, } \\
\text { [1R-(1.alpha.,3.alpha.,4.beta.)]- }\end{array}$ & 103,468 \\
\hline 44.618 & 2-Pentadecanone, 6,10,14-trimethyl- & 69,726 \\
\hline 45.482 & Dodecanoic acid, 3-hydroxy- & 256,424 \\
\hline 45.502 & n-Hexadecanoic acid & 335,278 \\
\hline 47.527 & 2,6-Octadiene-1,8-diol, 2,6-dimethyl- & $896,585.5$ \\
\hline 47.940 & 2(4H)-Benzofuranone, 5,6,7,7a-tetrahydro-4,4,7a-trimethyl- & $344,852.5$ \\
\hline 50.351 & Benzophenone & $173,741.5$ \\
\hline 51.518 & Vanillin & $206,667.5$ \\
\hline
\end{tabular}


Table A2. Results for the SGP sample fingerprint determination with indication of the retention time (RT) and abundance mean for every identified compound.

\begin{tabular}{|c|c|c|}
\hline RT & Compound Name & Abundance Mean \\
\hline 1.073 & Cyclopropyl methyl carbinol & 120,514 \\
\hline 3.273 & Hexanal & $575,125.5$ \\
\hline 3.405 & Methoxyacetic acid, tridecyl ester & 68,993 \\
\hline 3.430 & 3-Tridecene, $(Z)$ - & 68,920 \\
\hline 4.183 & 4-Pentenal, 2-ethyl- & 115,550 \\
\hline 4.460 & Sydnone, 3,3'-trimethylenedi- & 22,564 \\
\hline 5.214 & beta.-Myrcene & $1,018,173.5$ \\
\hline 5.260 & .beta.-Myrcene & 619,254 \\
\hline 5.490 & Ethanol, 2-[2-(4-pyridyl)ethylamino]- & 42,808 \\
\hline 5.921 & Cyclohexene, 4-ethenyl-1,4-dimethyl- & 639,379 \\
\hline 6.702 & 5-Aminoisoxazole & 42,411 \\
\hline 6.706 & 3-Hexenal, (Z)- & 364,986 \\
\hline 7.009 & $\mathrm{~N}$-(Trifluoroacetyl)-N,O, $\mathrm{O}^{\prime}, \mathrm{O}^{\prime \prime}$-tetrakis(trimethylsilyl)norepinephrine & 118,904 \\
\hline 7.601 & beta.-Ocimene & 110,410 \\
\hline 7.615 & .alpha.-Pinene & 433,550 \\
\hline 8.170 & 3-Carene & 119,228 \\
\hline 8.215 & Tricyclo[2.2.1.0(2,6)]heptane, 1,7,7-trimethyl- & 156,509 \\
\hline 8.229 & beta.-Ocimene & 630,021 \\
\hline 8.464 & Dodecane, 4,6-dimethyl- & 129,460 \\
\hline 8.475 & Undecane, 3,8-dimethyl- & 507,030 \\
\hline 10.385 & trans,cis-2,6-Nonadienyl acetate & 34,989 \\
\hline 10.467 & Tridecane, 6-methyl- & 210,574 \\
\hline 10.497 & Nonane, 4,5-dimethyl- & 37,215 \\
\hline 10.734 & Dodecane, 4,6-dimethyl- & $338,715.5$ \\
\hline 11.000 & 3-Hepten-1-ol, (Z)- & 226,106 \\
\hline 11.151 & 3-Ethyl-3-methylheptane & 239,089 \\
\hline 11.425 & cis-Aconitic anhydride & 27,787 \\
\hline 11.556 & 4-Heptafluorobutyroxytridecane & 524,738 \\
\hline 11.586 & Nonane, 4,5-dimethyl- & 150,122 \\
\hline 11.930 & 5-Hepten-2-one, 6-methyl- & 378,933 \\
\hline 12.318 & 2-Isopropyl-5-methyl-1-heptanol & 195,059 \\
\hline 12.323 & Oxalic acid, allyl octadecyl ester & 89,397 \\
\hline 12.380 & 1-Alanine, N-(cyclohexylcarbonyl)-, heptadecyl ester & 37,359 \\
\hline 14.688 & Nonanal & 113,348 \\
\hline 15.129 & 1-Methoxy-3-hydroxymethylheptane & 119,355 \\
\hline 15.620 & Heptadecane, 2,6,10,14-tetramethyl- & 65,889 \\
\hline 15.635 & Tridecane & 183,448 \\
\hline 16.195 & 3-Undecene, (Z)- & 63,096 \\
\hline 16.220 & 2-Nonenal, (Z)- & 147,528 \\
\hline 16.460 & 2-(3-Bromopropyl)-[1,3]dioxolane & 28,267 \\
\hline 18.280 & Ammonium acetate & 187,763 \\
\hline 18.330 & Methoxyacetic acid, hexyl ester & 48,206 \\
\hline 18.390 & 1,4-Hexadiene, 5-methyl- & 261,153 \\
\hline 18.429 & Cyclohexan-1,4,5-triol-3-one-1-carboxylic acid & 619,199 \\
\hline 18.661 & Furfural & 345,710 \\
\hline 19.005 & Methoxyacetic acid, 2-tridecyl ester & 57,046 \\
\hline 19.022 & Nonane, 3-methyl-5-propyl- & 417,744 \\
\hline 19.055 & Nonane, 4,5-dimethyl- & 72,220 \\
\hline 19.600 & Butane, 1-(ethenyloxy)- & 23,034 \\
\hline 19.715 & 2,3-Hexadiene, 2-methyl- & 388,031 \\
\hline 20.635 & 2-Propyl-1-pentanol & 135,168 \\
\hline 21.037 & Benzaldehyde & 246,318 \\
\hline 21.250 & Undecane, 3,6-dimethyl- & 147,124 \\
\hline 21.466 & R-Limonene & 197,652 \\
\hline 21.730 & Pyrrolidine-2,4-dione & 21,913 \\
\hline 21.764 & Dodecane, 2,6,11-trimethyl- & 130,862 \\
\hline
\end{tabular}


Table A2. Cont.

\begin{tabular}{|c|c|c|}
\hline RT & Compound Name & Abundance Mean \\
\hline 21.770 & Decane, 2-methyl- & 37,031 \\
\hline 22.158 & 1,5-Heptadiene, 2,3,6-trimethyl- & $635,307.5$ \\
\hline 23.267 & 6-Octen-1-ol, 3,7-dimethyl-, acetate & 589,174 \\
\hline 23.301 & Cyclopropanemethanol, .alpha.,2-dimethyl-2-(4-methyl-3-pentenyl)-, [1.alpha.(R*),2.alpha.]- & $1,041,462$ \\
\hline 23.660 & N-[2,2,2-Trifluoro-1-(isopropylamino)-1-(trifluoromethyl)ethyl]isovaleramide & 197,837 \\
\hline 24.198 & 1,6,10-Dodecatrien-3-ol, 3,7,11-trimethyl- & $18,728,058$ \\
\hline 24.205 & 1-Bromo-3,7-dimethyl-2,6-octadiene & $31,337,534$ \\
\hline 24.306 & Linalyl acetate & $10,646,193$ \\
\hline 25.300 & 3-hydroxy-2-methyl-5-(prop-1-en-2-yl)cyclohexanone & 105,570 \\
\hline 26.919 & Oxalic acid, ethyl neopentyl ester & 276,546 \\
\hline 26.940 & Undecane, 2-methyl- & 248,945 \\
\hline 27.153 & Ethanol, 2-(2-ethoxyethoxy)- & 337,777 \\
\hline 27.405 & 1,5-Heptadiene, 2,5-dimethyl-3-methylene- & 127,621 \\
\hline 27.590 & Cyclohexane, 1R-acetamido-2,3-cis-epoxy-4-cis-formyloxy- & 41,150 \\
\hline 27.948 & Acetophenone & 217,637 \\
\hline 28.322 & d-Menthol & 135,041 \\
\hline 30.080 & 1-Pentene, 5-(2,2-dimethylcyclopropyl)-2-methyl-4-methylene- & 495,428 \\
\hline 30.086 & $(-)$-cis-Myrtanol & 169,778 \\
\hline 30.505 & Acetic acid, cyano- & 116,530 \\
\hline 30.842 & Cyclobutane, 1,2-bis(1-methylethenyl)-, trans- & $607,249.5$ \\
\hline 31.440 & .alpha.-Terpineol & $3,145,562.5$ \\
\hline 32.278 & Heptafluorobutanoic acid, 2-(1-adamantyl)ethyl ester & 611,947 \\
\hline 32.279 & 2,4-Methano-1H-indene, 4-chlorooctahydro- & 186,219 \\
\hline 32.657 & .beta.-Bisabolene & $192,658.5$ \\
\hline 32.958 & 2,6-Octadienal, 3,7-dimethyl-, (E)- & $342,345.5$ \\
\hline 33.300 & 1-Bromo-3,7-dimethyl-2,6-octadiene & $1,139,696$ \\
\hline 33.680 & 2H-Pyran-3-ol, 6-ethenyltetrahydro-2,2,6-trimethyl- & 138,117 \\
\hline 34.317 & Dispiro[4.2.4.2]tetradecane & 118,050 \\
\hline 34.327 & Cis-8-ethyl-exo-tricyclo[5.2.1.0(2.6)]decane & 66,678 \\
\hline 34.660 & 1-Bromo-3,7-dimethyl-2,6-octadiene & $1,387,273$ \\
\hline 36.273 & 5-Hepten-1-ol, 2-ethenyl-6-methyl- & 386,406 \\
\hline 36.587 & Anethole & 232,191 \\
\hline 37.173 & Lanceol, cis & 198,363 \\
\hline 37.177 & Ionone & 218,275 \\
\hline 37.344 & 1,4-Methanobenzocyclodecene, 1,2,3,4,4a,5,8,9,12,12a-decahydro- & $517,247.3$ \\
\hline 37.793 & 1,2,4-Trioxolane, 3,5-dipropyl- & 599,431 \\
\hline 37.811 & Octane, 1 -azido- & 718,189 \\
\hline 37.900 & 2,6,10-Dodecatrien-1-ol, 3,7,11-trimethyl-, (Z,E)- & 332,897 \\
\hline 38.200 & 2H-Azepin-2-one, hexahydro-4-methyl- & 111,168 \\
\hline 38.205 & 1-Undecene, 5-methyl- & 150,120 \\
\hline 38.453 & 2-Methylvaleroyl chloride & 184,447 \\
\hline 38.730 & Geranyl acetate, 2,3-epoxy- & 139,279 \\
\hline 39.503 & 2-Dimethyl(trimethylsilyl)silyloxytridecane & 37,938 \\
\hline 39.686 & 2-Butanone, 4-(2,6,6-trimethyl-2-cyclohexen-1-ylidene)- & $212,113.5$ \\
\hline 40.236 & 3-Decyn-2-ol & 108,829 \\
\hline 40.269 & 3-Tetradecyn-1-ol & 127,313 \\
\hline 40.807 & Cyclododeca-5,9-dien-1-ol, 2-methyl-, (Z,Z)- & 151,636 \\
\hline 41.095 & 1,5,5-Trimethyl-6-methylene-cyclohexene & 370,901 \\
\hline 41.107 & 1,3,6-Heptatriene, 2,5,6-trimethyl- & 312,389 \\
\hline 44.479 & 1-Heptyn-6-one & 88,109 \\
\hline 44.600 & 9-Decen-2-one, 5-methylene- & 126,372 \\
\hline 44.613 & 1-Heptyn-6-one & 278,250 \\
\hline 44.807 & 10-Undecyn-1-ol & 104,806 \\
\hline 44.819 & Cyclopropane, hexylidene- & 158,800 \\
\hline 46.771 & Acetic acid, cyano- & 106,057 \\
\hline 47.899 & 2(4H)-Benzofuranone, 5,6,7,7a-tetrahydro-4,4,7a-trimethyl- & $484,359.5$ \\
\hline 57.725 & Imidodicarbonic acid, diethyl ester & 132,177 \\
\hline
\end{tabular}


Table A3. Results for the SGL sample fingerprint determination with indication of the retention time (RT) and abundance mean for every identified compound.

\begin{tabular}{|c|c|c|}
\hline RT & Compound Name & Abundance Mean \\
\hline 0.879 & Acetic acid, cyano- & 56,772 \\
\hline 1.040 & Pentanal, 2,4-dimethyl- & 57,277 \\
\hline 1.071 & 1-Propen-2-ol, formate & 167,675 \\
\hline 2.285 & .alpha.-Pinene & $170,241.5$ \\
\hline 2.328 & 1,3,6-Octatriene, 3,7-dimethyl-, (Z)- & 363,519 \\
\hline 2.385 & (R)-(+)-Citronellic acid & 85,004 \\
\hline 2.460 & 3-Undecen-1-yne, (E)- & 7687 \\
\hline 3.225 & Hexanal & 28,897 \\
\hline 3.965 & Methanone, 1,3-dithian-2-ylphenyl- & 64,181 \\
\hline 6.013 & D-Limonene & $44,500,934$ \\
\hline 6.715 & 4-Pentenal, 2-methyl- & 50,578 \\
\hline 7.642 & .gamma.-Terpinene & $6,561,102$ \\
\hline 8.201 & beta.-Ocimene & 328,361 \\
\hline 8.607 & Benzene, 1-methyl-3-(1-methylethyl)- & $2,692,739.5$ \\
\hline 9.068 & 2-Carene & $3,351,302$ \\
\hline 9.078 & $(+)$-4-Carene & $3,540,274$ \\
\hline 10.465 & Octane, 2,3,3-trimethyl- & 44,003 \\
\hline 10.752 & Undecane, 3,8-dimethyl- & 74,779 \\
\hline 11.947 & 5-Hepten-2-one, 6-methyl- & $273,176.5$ \\
\hline 13.846 & 1-Octanol, 3,7-dimethyl-, (S)- & 180,675 \\
\hline 14.722 & Nonanal & 92,985 \\
\hline 15.668 & Tridecane & 139,294 \\
\hline 16.709 & Benzene, 2-ethenyl-1,3-dimethyl- & 191,674 \\
\hline 16.740 & o-Isopropenyltoluene & 194,054 \\
\hline 18.399 & Cyclohexan-1,4,5-triol-3-one-1-carboxylic acid & 361,809 \\
\hline 18.408 & Glycidol & 717,548 \\
\hline 18.670 & Furfural & 621,339 \\
\hline 18.970 & Copaene & 551,737 \\
\hline 18.986 & .alfa.-Copaene & 507,260 \\
\hline 19.180 & Decane, 5-propyl- & 88,193 \\
\hline 19.434 & 6-Octenal, 3,7-dimethyl-, (R)- & 837,850 \\
\hline 19.699 & 3-Octen-2-ol, (Z)- & 451,255 \\
\hline 19.722 & Cyclopropane, trimethylmethylene- & 866,370 \\
\hline 20.190 & E-1,5,9-Decatriene & 64,911 \\
\hline 20.665 & 1-Methoxy-3-hydroxymethylheptane & 126,181 \\
\hline 21.051 & 1,2,4-Trioxolane, 3-methyl-5-phenyl- & 59,002 \\
\hline 21.430 & Octane, 5-ethyl-2-methyl- & 168,365 \\
\hline 21.683 & (Z,Z)-.alpha.-Farnesene & 330,622 \\
\hline 21.813 & Nonane, 5-(2-methylpropyl)- & 161,847 \\
\hline 22.189 & 3-Ethyl-1,5-octadiene & 224,260 \\
\hline 23.256 & trans-p-mentha-1(7),8-dien-2-ol & 842,313 \\
\hline 23.272 & cis-p-mentha-1(7),8-dien-2-ol & 736,608 \\
\hline 24.139 & 1-Bromo-3,7-dimethyl-2,6-octadiene & $8,422,457$ \\
\hline 24.146 & .beta.-Myrcene & $7,426,440$ \\
\hline 24.450 & Caryophyllene & $2,412,339$ \\
\hline 24.803 & Cyclohexane, 1-ethenyl-1-methyl-2,4-bis(1-methylethenyl)- & $1,661,763$ \\
\hline 24.828 & cis-.alpha.-Bisabolene & $1,997,395$ \\
\hline 25.130 & Dodecanal & 957,818 \\
\hline 25.148 & trans-2-Dodecen-1-ol, trifluoroacetate & 522,026 \\
\hline 26.458 & Cyclohexane, 4-methyl-2-methylene-1-(1-methylethylidene)- & 236,924 \\
\hline 27.055 & Pentadecane & 615,120 \\
\hline 27.122 & Heptadecane, 2,6,10,14-tetramethyl- & 369,320 \\
\hline 27.928 & 3-Tetradecyn-1-ol & 964,333 \\
\hline 27.958 & trans-2-Dodecen-1-ol, trifluoroacetate & 840,881 \\
\hline 28.359 & 1,4,7,-Cycloundecatriene, 1,5,9,9-tetramethyl-, Z,Z,Z- & 245,910 \\
\hline 28.761 & 2,2-Dimethylpropanoic acid, 2-adamantyl ester & 255,092 \\
\hline
\end{tabular}


Table A3. Cont.

\begin{tabular}{|c|c|c|}
\hline RT & Compound Name & Abundance Mean \\
\hline 29.215 & Cycloisolongifolene & 97,234 \\
\hline 30.355 & 2,6-Octadienal, 3,7-dimethyl-, (E)- & $51,100,548.5$ \\
\hline 31.498 & .alpha.-Terpineol & $8,024,237$ \\
\hline 32.200 & (-)-Carvone & 653,884 \\
\hline 32.388 & Dispiro[4.2.4.2] tetradecane & 107,256 \\
\hline 32.450 & 3-Adamantanecarboxylic acid, phenyl ester & 701,488 \\
\hline 33.255 & 2,6-Octadienal, 3,7-dimethyl-, (E)- & $71,369,488.5$ \\
\hline 33.958 & Carveol & 117,489 \\
\hline 33.989 & Cycloheptane, 1,3,5-tris(methylene)- & 157,810 \\
\hline 34.465 & Naphthalene, 1,2,3,4,4a,5,6,7-octahydro-4a-methyl- & 102,571 \\
\hline 34.475 & $\begin{array}{c}\text { 1H-3a,7-Methanoazulene, 2,3,6,7,8,8a-hexahydro-1,4,9,9-tetramethyl-, } \\
\text { (1.alpha.,3a.alpha.,7.alpha.,8a.beta.)- }\end{array}$ & 90,857 \\
\hline 34.689 & 1-Bromo-3,7-dimethyl-2,6-octadiene & 594,352 \\
\hline 35.305 & 7-Octen-1-ol, 3,7-dimethyl-, (S)- & 473,977 \\
\hline 36.040 & Z,Z,Z-4,6,9-Nonadecatriene & 914,01 \\
\hline 36.294 & 5-Hepten-1-ol, 2-ethenyl-6-methyl- & $1,012,776$ \\
\hline 36.612 & Anethole & 319,573 \\
\hline 37.369 & 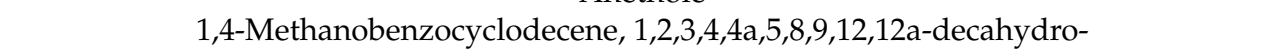 & $867,511.5$ \\
\hline 37.929 & 5-Hepten-1-ol, 2-ethenyl-6-methyl- & $1,881,320$ \\
\hline 37.939 & 1-Bromo-3,7-dimethyl-2,6-octadiene & $2,378,768$ \\
\hline 38.473 & 1-Hexene, 3,4,5-trimethyl- & $2,227,084.5$ \\
\hline 39.175 & 2-Bromosebacic acid, bis(trimethylsilyl) ester & 120,406 \\
\hline 39.715 & 2-Butanone, 4-(2,6,6-trimethyl-2-cyclohexen-1-ylidene)- & 172,929 \\
\hline 40.354 & Caryophyllene & 167,562 \\
\hline 41.044 & 2-Butanone, 4-(2,6,6-trimethyl-1-cyclohexen-1-yl)- & 182,625 \\
\hline 41.120 & 11,11-Dimethyl-spiro[2,9]dodeca-3,7-dien & 156,106 \\
\hline 41.352 & 5-Hepten-2-one, 6-methyl- & 57,635 \\
\hline 41.943 & 2-Cyclohexen-1-one, 6-(1-hydroxy-1-methylethyl)-3-methyl- & 71,111 \\
\hline 43.753 & 1-Nitro-2-propanone & 369,292 \\
\hline 44.620 & 1-Heptyn-6-one & 806,489 \\
\hline 44.628 & Methyl Isobutyl Ketone & 840,137 \\
\hline 44.750 & trans,trans-2,6-Dimethyl-2,6-octadiene-1,8-diol & 174,272 \\
\hline 47.500 & $\begin{array}{c}\text { Cyclopropaneoctanoic acid, 2-[[2-[(2-ethylcyclopropyl)methyl]cyclopropyl]methyl]-, methyl } \\
\text { ester }\end{array}$ & 105,937 \\
\hline 47.515 & Tetraacetyl-d-xylonic nitrile & 34,187 \\
\hline 47.917 & 2(4H)-Benzofuranone, 5,6,7,7a-tetrahydro-4,4,7a-trimethyl- & 481,958 \\
\hline 48.378 & Cycloheptane, 4-methylene-1-methyl-2-(2-methyl-1-propen-1-yl)-1-vinyl- & 99,068 \\
\hline 52.790 & 1-Propanamine, N-nitro- & 37,512 \\
\hline 52.992 & 1-Butanol & 59,088 \\
\hline
\end{tabular}

Table A4. Results for the SGM sample fingerprint determination with indication of the retention time (RT) and abundance mean for every identified compound.

\begin{tabular}{ccc}
\hline RT & Compound Name & Abundance Mean \\
\hline 0.018 & Acetic acid, cyano- & 63,013 \\
0.825 & Ethanol, 2-(vinyloxy)- & 60,490 \\
1.055 & Hydroperoxide, 1-methylethyl & 85,713 \\
1.120 & Ether, 2-chloro-1-propyl isopropyl & 63,783 \\
3.259 & Hexanal & 352,944 \\
3.350 & Glutaraldehyde & 150,508 \\
3.355 & 3-Penten-2-ol & 315,320 \\
3.440 & 1,2,15-Pentadecanetriol & 149,001 \\
3.490 & Trifluoromethanesulfonyl imidazole & 146,098 \\
3.540 & Acetic acid, cyano- & 63,215 \\
\hline
\end{tabular}


Table A4. Cont.

\begin{tabular}{|c|c|c|}
\hline RT & Compound Name & Abundance Mean \\
\hline 4.239 & 9-Tetradecen-1-ol, acetate, (E)- & 81,718 \\
\hline 5.184 & 2-Octyn-1-ol & 825,999 \\
\hline 5.211 & .beta.-Myrcene & 501,590 \\
\hline 5.665 & 2-Heptanone & 127,653 \\
\hline 5.912 & D-Limonene & 201,138 \\
\hline 5.918 & Cyclohexene, 4-ethenyl-1,4-dimethyl- & 109,577 \\
\hline 6.190 & 3-Pyridinecarbonitrile, 4-(methoxymethyl)-6-methyl-2-(2-propenyloxy)- & 64,607 \\
\hline 6.706 & 2-Hexenal & 151,942 \\
\hline 6.714 & (1-Allylcyclopropyl)methanol & 133,747 \\
\hline 6.957 & $\mathrm{~N}-\left(\right.$ Trifluoroacetyl)-N, $\mathrm{O}, \mathrm{O}^{\prime}, \mathrm{O}^{\prime \prime}$-tetrakis(trimethylsilyl)norepinephrine & 55,876 \\
\hline 7.511 & Furfuryl heptanoate & 99,402 \\
\hline 7.556 & .alpha.-Pinene & 97,319 \\
\hline 7.630 & 4-Terpinenyl acetate & 61,282 \\
\hline 8.220 & beta.-Ocimene & 235,507 \\
\hline 8.486 & Undecane, 3,8-dimethyl- & 261,838 \\
\hline 8.499 & Dodecane, 4,6-dimethyl- & 334,363 \\
\hline 8.784 & Octane, 2,3,3-trimethyl- & 140,125 \\
\hline 9.045 & (+)-4-Carene & 55,258 \\
\hline 10.420 & trans-.beta.-Terpinyl pentanoate & 98,048 \\
\hline 10.485 & Methoxyacetic acid, 2-methylpropyl ester & 72,844 \\
\hline 10.729 & Undecane, 2-methyl- & 153,807 \\
\hline 10.739 & Nonane, 5-(2-methylpropyl)- & 210,592 \\
\hline 10.963 & Butanamide, 3-cyclohexylamino-4-hydroxy-N-cyclohexyl- & 233,226 \\
\hline 10.972 & Z-1,8-Dodecadiene & 197,182 \\
\hline 11.190 & Nonane, 1-iodo- & 843,66 \\
\hline 11.265 & 2,4-Pentanedione, 3-ethyl- & 65,334 \\
\hline 11.453 & 1-Pentene, 5-chloro- & $326,317.5$ \\
\hline 11.595 & Undecane, 2,8-dimethyl- & 101,042 \\
\hline 11.910 & 5-Hepten-2-one, 6-methyl- & $361,742.5$ \\
\hline 12.318 & Trichloroacetic acid, tridecyl ester & 59,185 \\
\hline 14.315 & Diazene, dicyclohexyl-, 1,2-dioxide & 61,943 \\
\hline 14.698 & Nonanal & 167,658 \\
\hline 15.146 & 2-Decen-1-ol & 146,286 \\
\hline 15.591 & Heptadecane, 2,6,10,14-tetramethyl- & 59,042 \\
\hline 15.627 & Dodecane, 2-methyl- & 75,909 \\
\hline 16.206 & 5-Tridecene, $(Z)-$ & 68,987 \\
\hline 16.267 & 2-Octyn-1-ol & 71,981 \\
\hline 18.250 & 2,3-Epoxybutane & 411,295 \\
\hline 18.445 & 6-Nonenal, (Z)- & 530,076 \\
\hline 18.452 & Imidazole, 2-amino-5-[(2-carboxy)vinyl]- & 245,253 \\
\hline 18.654 & Furfural & $266,284.5$ \\
\hline 19.036 & Nonane, 5-(1-methylpropyl)- & 138,397 \\
\hline 19.039 & Nonane, 3-methyl-5-propyl- & 243,464 \\
\hline 19.698 & 2,3-Hexadiene, 2-methyl- & 277,170 \\
\hline 20.606 & 1-Pentanol, 2-ethyl-4-methyl- & 129,402 \\
\hline 20.995 & Benzaldehyde & 165,013 \\
\hline 21.054 & 1-Benzamido-N-benzyl-1-[.alpha.-(2-pyridylthio)benzylidene]acetamide & 119,058 \\
\hline 21.205 & Nonane, 4,5-dimethyl- & 83,886 \\
\hline 21.426 & R-Limonene & 119,271 \\
\hline 21.758 & Dodecane, 4-methyl- & 78,992 \\
\hline 22.139 & 1,5-Heptadiene, 2,3,6-trimethyl- & 209,903 \\
\hline 23.194 & Heptanal, 2-methyl- & 278,302 \\
\hline 23.262 & 2-Octen-1-ol, 3,7-dimethyl- & 450,603 \\
\hline 23.615 & 2-Heptafluorobutyroxydodecane & 70,417 \\
\hline 24.087 & 1-Bromo-3,7-dimethyl-2,6-octadiene & $9,842,404$ \\
\hline 25.104 & Oxirane, decyl- & 134,290 \\
\hline 25.211 & Dihydrocarvyl acetate & 90,710 \\
\hline
\end{tabular}


Table A4. Cont.

\begin{tabular}{|c|c|c|}
\hline RT & Compound Name & Abundance Mean \\
\hline 26.920 & Tridecane & 151,803 \\
\hline 26.937 & Pentadecane & 175,135 \\
\hline 27.128 & Ethanol, 2-(2-ethoxyethoxy)- & $248,708.5$ \\
\hline 27.364 & Dispiro[2.0.2.5] undecane, 8-methylene- & 120,439 \\
\hline 27.894 & S-Benzoyl-N-(O-hydroxybenzylidene)thiohydroxylamine & 87,628 \\
\hline 28.021 & 2-Decene, (Z)- & 71,624 \\
\hline 28.284 & Cyclohexanol, 5-methyl-2-(1-methylethyl)-, [1S-(1.alpha.,2.alpha.,5.beta.)]- & 60,158 \\
\hline 30.084 & Longipinene epoxide & 200,527 \\
\hline 30.135 & cis-p-mentha-1(7),8-dien-2-ol & 89,537 \\
\hline 30.355 & Valeric acid, 3-tridecyl ester & 80,075 \\
\hline 30.565 & Acetaldoxime & 68,044 \\
\hline 30.803 & Cyclobutane, 1,2-bis(1-methylethenyl)-, trans- & $211,358.5$ \\
\hline 31.404 & alpha.-Terpineol & $762,821.5$ \\
\hline 32.214 & 2,2-Dimethylpropanoic acid, 2-adamantyl ester & 60,028 \\
\hline 32.296 & 2,4-Methano-1H-indene, 4-chlorooctahydro- & 118,582 \\
\hline 32.590 & cis-sesquisabinene hydrate & 117,388 \\
\hline 32.929 & 2,6-Octadien-1-ol, 2,7-dimethyl- & $89,883.5$ \\
\hline 33.278 & 1-Bromo-3,7-dimethyl-2,6-octadiene & 288,750 \\
\hline 33.284 & 4-Hexen-1-ol, 5-methyl-2-(1-methylethenyl)-, acetate & 343,381 \\
\hline 33.572 & Cyclopentane, 1-ethyl-3-methyl-, trans- & 52,106 \\
\hline 33.967 & Pentanal & 185,683 \\
\hline 34.280 & Cyclododeca-5,9-dien-1-ol, 2-methyl-, (Z,Z)- & 84,052 \\
\hline 34.310 & Cis-8-ethyl-exo-tricyclo[5.2.1.0(2.6)]decane & 65,264 \\
\hline 34.643 & 2,6-Octadien-1-ol, 2,7-dimethyl- & 492,969 \\
\hline 34.648 & .beta.-Myrcene & 508,110 \\
\hline 36.243 & 5-Hepten-1-ol, 2-ethenyl-6-methyl- & 133,316 \\
\hline 36.577 & Anethole & 199,512 \\
\hline 37.160 & Andrographolide & 77,139 \\
\hline 37.584 & 1,4-Methanobenzocyclodecene, 1,2,3,4,4a,5,8,9,12,12a-decahydro- & $696,692.5$ \\
\hline 37.779 & Hexanal & $1,321,771$ \\
\hline 37.793 & 1,2,4-Trioxolane, 3,5-dipropyl- & 219,894 \\
\hline 37.875 & .beta.-Myrcene & 172,198 \\
\hline 38.180 & 2,5-Pyrrolidinedione, 1-ethyl- & 131,028 \\
\hline 38.429 & 2-Butanone, 3-methyl-1-phenyl- & 153,622 \\
\hline 38.435 & 4-Ethyl-1-hexyn-3-ol & 192,370 \\
\hline 38.771 & Cyclopropane, 1-(1'-propenyl)-2-hydroxymethyl- & 75,503 \\
\hline 39.686 & Acetic acid, 6,6-dimethyl-2-methylene-7-(3-oxobutylidene)oxepan-3-ylmethyl ester & 61,416 \\
\hline 40.818 & 3-Tridecen-1-yne, (Z)- & 69,714 \\
\hline 40.819 & $9,12,15$-Octadecatrienal & 97,882 \\
\hline 41.011 & 2-Butanone, 4-(2,6,6-trimethyl-1-cyclohexen-1-yl)- & 102,986 \\
\hline 41.093 & cis-sesquisabinene hydrate & 224,962 \\
\hline 44.166 & Adenine-9-propanoic acid, alpha.-t-butoxycarbonylamino- & 102,494 \\
\hline 44.463 & 1-Heptyn-6-one & 98,989 \\
\hline 44.469 & Methyl Isobutyl Ketone & 63,708 \\
\hline 44.595 & 9-Decen-2-one, 5-methylene- & 143,812 \\
\hline 45.240 & Propanal, 2-methyl-, 2-propenylhydrazone & 52,896 \\
\hline 45.470 & Cyclopentaneundecanoic acid & 64,619 \\
\hline 47.888 & 2(4H)-Benzofuranone, 5,6,7,7a-tetrahydro-4,4,7a-trimethyl- & 283,652 \\
\hline
\end{tabular}


Table A5. Results for the TBV sample fingerprint determination with indication of the retention time (RT) and abundance mean for every identified compound.

\begin{tabular}{|c|c|c|}
\hline RT & Compound Name & Abundance Mean \\
\hline 0.730 & Acetic acid, cyano- & 94,784 \\
\hline 0.815 & Propane & 115,993 \\
\hline 0.881 & N-(2-Methylacryloyl)imidazola & 114,248 \\
\hline 1.040 & Allyl acetate & 49,897 \\
\hline 1.081 & 2-Hexanone, 4-hydroxy-5-methyl-3-propyl- & 221,553 \\
\hline 1.425 & Pentan-2-ol, 1-tert-buthylamino-4-methyl- & 37,600 \\
\hline 1.438 & Butanal, 2-methyl- & 100,607 \\
\hline 1.490 & Butanal, 3-methyl- & 84,716 \\
\hline 1.947 & 3-Aminopyrrolidine & 207,498 \\
\hline 1.951 & 1,3-Dioxane-4,6-dione, 2,2-dimethyl- & 225,463 \\
\hline 2.030 & Acetamide, N-[2-(4-methylphenoxy)ethyl]- & 65,728 \\
\hline 2.045 & Azacyclodecan-5-ol & 45,434 \\
\hline 3.284 & Hexanal & $1,398,458.5$ \\
\hline 3.655 & Triallyl phosphate & 23,541 \\
\hline 5.575 & Acetonitrile, bromo- & 26,297 \\
\hline 5.675 & Propane, 2-(ethenyloxy)- & 24,723 \\
\hline 5.730 & 2,3-Anhydro-d-galactosan & 30,652 \\
\hline 5.740 & Heptanal & 147,257 \\
\hline 5.765 & Butanal, 3-methyl- & 149,962 \\
\hline 5.953 & Tetrahydropyrrolo[1,2-a]azetidin-2-one & 193,616 \\
\hline 5.957 & Murexide & 90,456 \\
\hline 6.030 & 5-[2-Thienyl]hydantoin & 77,334 \\
\hline 6.702 & 2-Hexenal & 676,577 \\
\hline 6.985 & $\mathrm{~N}$-(Trifluoroacetyl)-N,O, $\mathrm{O}^{\prime}, \mathrm{O}^{\prime \prime}$-tetrakis(trimethylsilyl)norepinephrine & 706,731 \\
\hline 8.505 & Dodecane, 4-methyl- & 90,410 \\
\hline 9.655 & Octanal & 66,979 \\
\hline 9.658 & 1,6-Anhydro-3,4-dideoxy-.beta.-D-manno-hexapyranose & 54,785 \\
\hline 11.959 & 5-Hepten-2-one, 6-methyl- & 262,786 \\
\hline 14.740 & Nonanal & $373,934.5$ \\
\hline 15.147 & Ethanol, 2-butoxy- & 138,163 \\
\hline 15.165 & 2,5-Dimethyl-1-hepten-4-ol & 121,419 \\
\hline 18.282 & Ammonium acetate & $2,141,214$ \\
\hline 18.701 & Furfural & $1,136,801$ \\
\hline 19.103 & Nonane, 5-(2-methylpropyl)- & 246,297 \\
\hline 20.714 & 1-Hexanol, 2-ethyl- & 75,528 \\
\hline 21.122 & Benzaldehyde & $4,085,838.5$ \\
\hline 21.846 & Undecane, 3,7-dimethyl- & 316,312 \\
\hline 22.135 & Cycloheptano[d]imidazolidine, 1,3-dihydroxy-2-methyl- & 103,470 \\
\hline 23.290 & Propanoic acid & $200,796.5$ \\
\hline 24.141 & 5-Hepten-1-ol, 2-ethenyl-6-methyl- & 197,773 \\
\hline 24.456 & 1H-Pyrazole, 1,3,5-trimethyl- & 783,099 \\
\hline 24.467 & 2-Furancarboxaldehyde, 5-methyl- & 686,396 \\
\hline 26.464 & Benzenemethanol, .alpha.-(1-ethenylpentyl)-.alpha.-methyl- & 96,576 \\
\hline 27.076 & Undecane, 2-methyl- & 255,153 \\
\hline 27.700 & Benzaldehyde, 2-methyl- & $129,230.5$ \\
\hline 28.036 & Acetophenone & 69,030 \\
\hline 30.240 & Pent-3-en-2-one, 4-methyl-, oxime & 127,754 \\
\hline 30.255 & 4-Methoxy-2,3-dimethyl-2,3-dihydroazete & 103,964 \\
\hline 30.487 & 2(3H)-Furanone, 5-ethyldihydro- & $554,528.5$ \\
\hline 32.606 & 2,3-Dimethyldodecane & 55,910 \\
\hline 32.606 & Tetradecane, 2-methyl- & 71,677 \\
\hline 33.011 & Propanoic acid, 3-hydroxy-2-[2-\{[benzyloxy)carbonyl]amino\}acetyl)amino] & 43,642 \\
\hline 34.024 & Pentanoic acid & $72,953.5$ \\
\hline 34.312 & Methyl salicylate & 34,235 \\
\hline 35.313 & 2(3H)-Furanone, dihydro-5-propyl- & $3,103,701.5$ \\
\hline 36.641 & 1-Octadecanesulphonyl chloride & $85,226.5$ \\
\hline
\end{tabular}


Table A5. Cont.

\begin{tabular}{|c|c|c|}
\hline RT & Compound Name & Abundance Mean \\
\hline 37.648 & 1,4-Methanobenzocyclodecene, 1,2,3,4,4a,5,8,9,12,12a-decahydro- & $91,628.5$ \\
\hline 37.840 & Hexanoic acid & $887,087.5$ \\
\hline 37.928 & Phenol, 2-methoxy- & 624,495 \\
\hline 38.239 & 2,5-Pyrrolidinedione, 1-ethyl- & $345,675.5$ \\
\hline 38.411 & Benzyl-diseryl phosphate & 193,527 \\
\hline 38.413 & Benzene, [(2-propenyloxy)methyl]- & 326,206 \\
\hline 38.993 & 2(3H)-Furanone, 5-butyldihydro- & $567,940.5$ \\
\hline 39.296 & Phenylethyl Alcohol & 81,672 \\
\hline 40.533 & Maltol & $3,012,548.5$ \\
\hline 40.765 & Heptanoic acid & 213,937 \\
\hline 40.869 & 2-Pentenenitrile, 4,4-dimethyl- & 282,191 \\
\hline 40.879 & 7-Nonynoic acid & 362,88 \\
\hline 41.025 & 2-Hexenoic acid & 206,927 \\
\hline 41.060 & 1H-Azepine, hexahydro-1-nitroso- & 33,836 \\
\hline 41.175 & 1-Dodecene & 170,528 \\
\hline 41.180 & E-11,13-Tetradecadien-1-ol & 25,182 \\
\hline 41.435 & Furan, $2,2^{\prime}$-[oxybis(methylene)]bis- & 124,175 \\
\hline 41.845 & Benzaldehyde, 4-methoxy- & $2,417,723$ \\
\hline 42.050 & 1H-Pyrrole-2-carboxaldehyde & 73,396 \\
\hline 42.195 & Benzene, (2-methyl-1-methylenebutyl)- & 90,494 \\
\hline 42.201 & Cinnamaldehyde, (E)- & 126,790 \\
\hline 42.348 & Benzene, 1,4-dimethoxy-2-methyl- & 85,105 \\
\hline 43.259 & Octanoic acid & 731,575 \\
\hline 44.420 & 4-Acetylanisole & 102,679 \\
\hline 44.425 & 3-Methoxyacetophenone & 138,444 \\
\hline 44.526 & 2(3H)-Furanone, 5-hexyldihydro- & 597,573 \\
\hline 44.745 & Ethanol, 2-phenoxy- & 39,625 \\
\hline 44.909 & 1,3,5-Cycloheptatriene, 1-methoxy- & $58,650.5$ \\
\hline 45.506 & Nonanoic acid & $69,740.5$ \\
\hline 46.205 & Piperonal & $87,421.5$ \\
\hline 46.704 & 2-n-Butyl furan & 23,192 \\
\hline 47.458 & Benzenemethanol, 4-methoxy- & $421,101.5$ \\
\hline 47.590 & n-Decanoic acid & 300,368 \\
\hline 47.938 & 2(4H)-Benzofuranone, 5,6,7,7a-tetrahydro-4,4,7a-trimethyl- & $278,448.5$ \\
\hline 48.989 & .gamma.-Dodecalactone & 258,188 \\
\hline 49.980 & Benzoic acid & 62,533 \\
\hline 51.376 & 1,2-Benzenedicarboxylic acid, dihexyl ester & 26,249 \\
\hline 51.531 & Vanillin & $8,287,611.5$ \\
\hline 54.111 & 3-Hydroxy-4-methoxybenzyl alcohol & 51,514 \\
\hline
\end{tabular}

Table A6. Results for the EBP sample fingerprint determination with indication of the retention time (RT) and abundance mean for every identified compound.

\begin{tabular}{ccc}
\hline RT & Compound Name & Abundance Mean \\
\hline 0.189 & Carbamic acid, (cyanoacetyl)-, ethyl ester & 40,219 \\
0.690 & Acetic acid, cyano- & 71,328 \\
0.859 & 4-Heptanone, dimethylhydrazone & 68,187 \\
0.931 & 1-(4-Acetamidoanilino)-3,7-dimethylbenzo[4,5]imidazo[1,2-a]pyridine-4-carbonitrile & 42,303 \\
0.980 & Sulfide, methyl 1-methyl-2-butenyl & 44,455 \\
1.390 & $4 \mathrm{H}, 8 \mathrm{H}-[1,2,4]$ Triazino[3,4-b][1,3,4]thiadiazin-4-one, 7-amino-3-methyl- & 48,156 \\
1.430 & Butanal, 3-methyl- & 54,247 \\
1.504 & Acetic acid, cyano- & 24,296 \\
1.547 & 4-Penten-2-ol, 4-methyl- & 36,478 \\
1.719 & 2-Butyne-1,4-diol bis(.beta.-hydroxyethyl ether) & 29,900 \\
2.525 & 3-Hexenoic acid, ethyl ester, (Z)- & 21,487 \\
2.599 & dl-Ornithine & 27,137 \\
\hline
\end{tabular}


Table A6. Cont.

\begin{tabular}{|c|c|c|}
\hline RT & Compound Name & Abundance Mean \\
\hline 2.618 & Thiocyanic acid, 5-amino-3-methyl-4-isoxazolyl ester & 22,308 \\
\hline 2.740 & 5-Ethyl-2-methyl-pyridin-4-amine & 27,062 \\
\hline 3.220 & Hexanal & 95,779 \\
\hline 3.273 & Hexanal & 32,777 \\
\hline 3.295 & 1,3-Dioxane-4,6-dione, 5,5-dimethyl-2-(1-methylethylidene)- & 36,361 \\
\hline 3.308 & Butane, 1-(ethenyloxy)- & 82,998 \\
\hline 3.335 & 1-Propene, 3-methoxy- & 92,869 \\
\hline 3.400 & 5-Aminoisoxazole & 93,919 \\
\hline 3.420 & cis-Aconitic anhydride & 33,724 \\
\hline 3.435 & 2-Propanamine, N-ethyl-N-nitroso- & 24,872 \\
\hline 3.460 & Tris(aziridinomethyl)hydrazine & 24,606 \\
\hline 3.504 & Butane, 1-(ethenyloxy)- & 22,708 \\
\hline 3.505 & 4,5-Dicarboxy-1,2,3-triazole & 23,452 \\
\hline 5.125 & Formic acid, 1,1-dimethylethyl ester & 23,031 \\
\hline 5.150 & 1,2,4-Triazol-5-acetic acid, 3-amino- & 24,912 \\
\hline 5.212 & Ethanediamide, N-(1-methylpropyl)-N'-(3-pyridinylmethyl)- & 21,740 \\
\hline 5.225 & cis-Aconitic anhydride & 26,678 \\
\hline 5.330 & (+)-2-Carene, 4-.alpha.-isopropenyl- & 21,260 \\
\hline 5.740 & 3-(4-Methyl-piperazin-1-yl)-N-(4-trifluoromethoxy-phenyl)-propionamide & 25,237 \\
\hline 6.677 & Allyl methallyl ether & 54,578 \\
\hline 6.974 & $\mathrm{~N}$-(Trifluoroacetyl)-N,O,O', $\mathrm{O}^{\prime \prime}$-tetrakis(trimethylsilyl)norepinephrine & 69,040 \\
\hline 7.040 & N-Methyladrenaline, tri-TMS & 28,857 \\
\hline 7.503 & Cyclopropanecarboxylic acid & 21,350 \\
\hline 8.163 & Chlorocarbonyl t-butoxy sulfide & 30,269 \\
\hline 8.186 & 3-Buten-2-ol, 3-methyl- & 26,893 \\
\hline 8.455 & 3-Ethyl-3-methylheptane & 66,659 \\
\hline 9.740 & 1,4-Dioxa-2-decalone & 28,660 \\
\hline 10.738 & Decane, 3,7-dimethyl- & 46,542 \\
\hline 11.560 & 2-Bromononane & 23,532 \\
\hline 11.905 & 2-Ethyl-3-vinyloxirane & 23,682 \\
\hline 11.925 & 2-Pentenal, 2,4,4-trimethyl- & 28,175 \\
\hline 13.315 & Cyclohexanemethanol, .alpha.-ethyl- & 31,869 \\
\hline 14.310 & 6-Chloro-2,4-dihydroxy-1,3-dimethylpyrimidine & 21,426 \\
\hline 14.469 & Methyl piperidin-4-carboxylate & 21,730 \\
\hline 14.610 & Pyrrolizidine-3-one-5-ol, ethyl ether & 27,717 \\
\hline 14.672 & Nonanal & 61,648 \\
\hline 14.690 & p-Nitro carbanilic acid, n-heptyl ester & 23,421 \\
\hline 14.785 & 3,4,4,-Trimethyl-1-pentyn-3-ol & 24,211 \\
\hline 14.834 & 3,3-Dimethyl-2-hydroxy-2-phenylthiomorpholine & 28,086 \\
\hline 15.047 & Cyclohexane, 1,2-bis(t-butoxycarbonylmethoxy)- & 27,138 \\
\hline 17.085 & Cyanamide, N-allyl-N-[2-(2-hydroxy-2-methylpropyl)-3,3-dimethylcyclopropyl]methyl- & 34,017 \\
\hline 17.175 & 8.beta.-17.alpha.-Dihydroxy-desoxycorticosterone & 27,911 \\
\hline 17.505 & 1,2,4-Triazole, 4-[N-(2-hydroxyethyl)-N-nitro]amino- & 22,875 \\
\hline 17.557 & 4-Heptanol, 2-methyl- & 43,238 \\
\hline 18.316 & Ammonium acetate & 46,413 \\
\hline 18.370 & 1,2,4-Trioxolane, 3,5-dipropyl- & 46,649 \\
\hline 18.566 & 1,2-Cyclobutanedicarboxylic acid, 3-methyl-, dimethyl ester & 26,028 \\
\hline 18.639 & 2H-Pyran, 2-(3-butynyloxy)tetrahydro- & 33,812 \\
\hline 18.666 & trans-2,7-Dimethyl-3,6-octadien-2-ol & 41,759 \\
\hline 19.001 & 5-Ethyl-4-tridecanone & 32,467 \\
\hline 19.037 & Tetradecane, 5-methyl- & 27,346 \\
\hline 19.055 & 1-Butanol, 3-methyl-, nitrate & 30,550 \\
\hline 20.405 & Propenone, 3-dimethylamino-1-[3-(3-dimethylaminoacryloyl)-2,6-dihydroxyphenyl]- & 22,794 \\
\hline 20.461 & Sulfide, di(1,3-butadienyl)- & 28,315 \\
\hline 20.545 & 5,6,6-Trimethyl-hept-3-yne-2,5-diol & 26,021 \\
\hline 20.579 & 4-Hexen-2-one, 3-methyl- & 29,025 \\
\hline 20.582 & 1-Decene, 2,4-dimethyl- & 45,611 \\
\hline
\end{tabular}


Table A6. Cont.

\begin{tabular}{|c|c|c|}
\hline RT & Compound Name & Abundance Mean \\
\hline 20.970 & 3-tert-Butyl-5-chloro-2-hydroxybenzophenone & 26,089 \\
\hline 21.017 & 1-Benzamido-N-benzyl-1-[.alpha.-(2-pyridylthio)benzylidene]acetamide & 43,002 \\
\hline 21.020 & Bis[4-acetamidophenylsulfonyl]phenyl methane & 43,423 \\
\hline 21.105 & 1,2,5-Oxadiazol-3-amine, N-cyclopropyl-4-[5-(trichloromethyl)-1,2,4-oxadiazol-3-yl]- & 31,391 \\
\hline 21.172 & Oxalic acid, allyl decyl ester & 48,664 \\
\hline 21.714 & 5-Hydroxy-2,4,4-trimethyl-cyclopentane-1,3-dione & 28,464 \\
\hline 21.726 & Tetradecane, 4-ethyl- & 49,899 \\
\hline 22.143 & 3-Ethyl-1,5-octadiene & 65,512 \\
\hline 23.217 & 2-Norbornanone, 6-chloro-3,3-dimethyl-, exo- & 32,271 \\
\hline 23.230 & 1,2-Dihydrolinalool & 82,631 \\
\hline 23.265 & 2-Propenyl-3-vinyloxirane & 35,236 \\
\hline 24.021 & 2,6-Octadien-1-ol, 2,7-dimethyl- & 827,705 \\
\hline 24.036 & Linalyl acetate & 886,873 \\
\hline 24.803 & 2H-Pyran, 2-(3-butynyloxy)tetrahydro- & 25,758 \\
\hline 26.907 & Malonic acid, bis(2-trimethylsilylethyl ester & 52,354 \\
\hline 27.985 & 1,8-Dichlorooctane & 25,086 \\
\hline 28.235 & Methylene asparagine & 26,750 \\
\hline 28.269 & 2-Pyrrolidinone, 1-methyl- & 85,192 \\
\hline 28.271 & 3,3,3-Trifluoro-N-(2-fluorophenyl)-2-(trifluoromethyl)propionamide & 31,186 \\
\hline 30.675 & Oxalic acid, allyl nonyl ester & 26,882 \\
\hline 31.325 & .alpha.-Terpineol & $63,064.5$ \\
\hline 31.374 & 3-Methyl-2-methylene-5-oxopyrrolidine-3-carbonitrile & 31,392 \\
\hline 31.400 & trans-2,7-Dimethyl-3,6-octadien-2-ol & 26,447 \\
\hline 33.244 & trans,cis-2,6-Nonadien-1-ol & 25,713 \\
\hline 33.895 & Propanedioic acid, propyl- & 35,831 \\
\hline 34.580 & 5-(3,7-Dimethylocta-2,6-dienyl)-4-methyl-2,3-dihydrothiophene 1,1-dioxide & 22,011 \\
\hline 34.904 & 2H-Pyran-3-ol, 6-ethenyltetrahydro-2,2,6-trimethyl- & 25,268 \\
\hline 36.573 & Allyl heptanoate & 22,998 \\
\hline 37.752 & Heptanoic acid & $56,211.5$ \\
\hline 37.880 & .beta.-Myrcene & 29,088 \\
\hline 38.160 & 2,5-Pyrrolidinedione, 1-ethyl- & 62,446 \\
\hline 38.341 & Benzene, [(2-propenyloxy)methyl]- & 72,902 \\
\hline 38.344 & Benzyl alcohol & 84,220 \\
\hline 39.227 & Phenylethyl Alcohol & 46,827 \\
\hline 40.794 & Ethanone, 1-(1H-pyrrol-2-yl)- & $29,239.5$ \\
\hline 42.939 & 2-Butenediamide, 2-methyl-, (E)- & 24,382 \\
\hline 45.070 & Benzylamine, N-(3-chloro-2,2-dimethyl-1-phenylpropylidene)- & 25,983 \\
\hline 45.373 & Cyclopropanecarboxylic acid, cyclohexylmethyl ester & 23,678 \\
\hline 46.290 & 2-Amino-4-dimethylaminomethylenepentanedinitrile & 30,668 \\
\hline 47.859 & 2(4H)-Benzofuranone, 5,6,7,7a-tetrahydro-4,4,7a-trimethyl- & 35,368 \\
\hline 48.860 & 2H-Pyran-2-one, 5,6-dihydro-4-(2-methyl-3-methylene-1-buten-4-yl)- & 76,496 \\
\hline 48.921 & 3H-1,2,4-Triazole-3-thione, 2,4-dihydro-4-phenyl- & 36,542 \\
\hline 49.912 & 4-Piperidinepropanoic acid, 1-benzoyl-3-(2-chloroethyl)-, ethyl ester & 44,931 \\
\hline 52.555 & 1,2,3-Butanetriol & 25,538 \\
\hline 53.001 & Oxetane, 2-methyl-4-propyl- & 30,545 \\
\hline 56.669 & 2,5-Furandione, dihydro-3-methylene- & 29,961 \\
\hline
\end{tabular}

Table A7. Results for the EBL sample fingerprint determination with indication of the retention time (RT) and abundance mean for every identified compound.

\begin{tabular}{ccc}
\hline RT & Compound Name & Abundance Mean \\
\hline 0.886 & p-Dioxane, methylene- & 60,857 \\
2.270 & Hexanamide, 6-(2-oxocyclopentyl)-N-phenyl- & 97,276 \\
2.296 & 2-Hydroxy-3-pyrazin-2-ylacrylic acid & 53,348 \\
2.410 & 1,1'-(4-Methyl-1,3-phenylene)bis[3-(5-benzyl-1,3,4-thiadiazol-2-yl)urea] & 66,587 \\
3.230 & Hexanal & 125,407 \\
4.240 & Cyclohexene, 1-methyl-4-(1-methylethyl)- & 415,553 \\
\hline
\end{tabular}


Table A7. Cont.

\begin{tabular}{|c|c|c|}
\hline RT & Compound Name & Abundance Mean \\
\hline 5.165 & beta.-Myrcene & $932,205.5$ \\
\hline 6.028 & D-Limonene & $20,772,492$ \\
\hline 6.083 & Cyclobutane, 1,2-bis(1-methylethenyl)-, trans- & $28,705,656$ \\
\hline 6.680 & 2-Hexenal & 350,397 \\
\hline 6.970 & 4-Methylcatechol, bis(trimethylsilyl) ether & 99,509 \\
\hline 7.608 & gamma.-Terpinene & $2,668,285.5$ \\
\hline 8.218 & 3-Nonen-1-yne, (Z)- & 185,302 \\
\hline 8.577 & Benzene, 1-methyl-3-(1-methylethyl)- & $1,380,619$ \\
\hline 9.032 & $(+)-4$-Carene & $369,547.5$ \\
\hline 10.477 & Decane, 2,4-dimethyl- & 59,486 \\
\hline 10.489 & Undecane, 2,7-dimethyl- & 147,641 \\
\hline 11.408 & Cyclopropaneethanol & $87,457.5$ \\
\hline 11.920 & 1-Hepten-6-one, 2-methyl- & 216,541 \\
\hline 13.323 & 1-Butanol, 3-methoxy- & 82,569 \\
\hline 14.474 & 3-Hexen-1-ol & 72,691 \\
\hline 14.653 & Nonanal & 227,838 \\
\hline 15.801 & 2-Penten-1-ol, 4-methyl- & 123,248 \\
\hline 17.298 & 2,6-Octadiene-1,8-diol, 2,6-dimethyl- & 143,284 \\
\hline 18.203 & Ammonium acetate & $594,590.5$ \\
\hline 18.619 & Pyrazole, 1,4-dimethyl- & 146,710 \\
\hline 18.640 & Furfural & 251,584 \\
\hline 18.926 & Copaene & 187,151 \\
\hline 19.482 & Acetic acid, hexyl ester & 223,391 \\
\hline 20.390 & Octane, 1-azido- & 48,281 \\
\hline 20.413 & Decanal & 82,253 \\
\hline 21.002 & Benzaldehyde & 147,588 \\
\hline 22.121 & 1,6-Heptadiene, 2,5,5-trimethyl- & 81,076 \\
\hline 22.161 & 1,5-Heptadiene, 2,3,6-trimethyl- & 245,420 \\
\hline 23.162 & 5-Nonenoic acid, methyl ester & 231,994 \\
\hline 23.204 & 1,2-Dihydrolinalool & 226,441 \\
\hline 23.628 & Cyclohexanol, 5-methyl-2-(1-methylethyl)-, acetate, (1.alpha.,2.beta.,5.beta.)- & 54,549 \\
\hline 23.656 & Menthyl acetate & 82,100 \\
\hline 24.079 & Linalyl acetate & $3,330,821$ \\
\hline 24.326 & 1,1-Cyclopropanedicarbonitrile, 2-butyl-2-methyl- & 176,787 \\
\hline 24.694 & trans-.alpha.-Bergamotene & 209,911 \\
\hline 26.318 & Benzenemethanol, .alpha.-(1-ethenylpentyl)-.alpha.-methyl- & 92,881 \\
\hline 26.945 & Arabino-Hex-1-enitol, 1,5-anhydro-2-deoxy- & 102,198 \\
\hline 27.845 & Oxiranemethanol, 2-phenyl- & 190,581 \\
\hline 27.871 & Cyclopropane, 1-bromo-2,2,3,3-tetramethyl-1-prop-1-ynyl- & 49,869 \\
\hline 28.261 & d-Menthol & $142,424.5$ \\
\hline 28.595 & 2-Bromopropionic acid, 2-pentyl ester & 79,505 \\
\hline 29.070 & Cycloisolongifolene & 120,477 \\
\hline 30.001 & 2,6-Octadienal, 3,7-dimethyl-, (Z)- & $535,579.5$ \\
\hline 30.495 & 2-Methyl-1-methylmannopyranoside & 167,380 \\
\hline 30.806 & 3-Cyclohexene-1-methanol, .alpha.,.alpha.,4-trimethyl-, acetate & 635,343 \\
\hline 30.824 & .alpha.-Terpineol & 702,887 \\
\hline 31.110 & 1-Cyclohexyl-2,2-dimethyl-1-propanol acetate & 79,379 \\
\hline 31.364 & L-.alpha.-Terpineol & $953,500.5$ \\
\hline 31.644 & Acetic acid, 1-(R)-phenylethyl ester & $152,399.5$ \\
\hline 32.078 & $(-)$-Carvone & 238,609 \\
\hline 32.618 & beta.-Bisabolene & 292,323 \\
\hline 32.907 & 2,6-Octadienal, 3,7-dimethyl-, (Z)- & $517,386.5$ \\
\hline 33.259 & Linalyl acetate & $180,568.5$ \\
\hline 33.570 & 7,8-Dibromo-4,4,7-trimethyl-hexahydro-benzo[1,3]dioxin-2-one & 31,710 \\
\hline 33.899 & Butanoic acid, 3-methyl- & 116,192 \\
\hline 34.202 & Methyl salicylate & 140,347 \\
\hline 34.653 & 2,6-Octadien-1-ol, 2,7-dimethyl- & 735,215 \\
\hline
\end{tabular}


Table A7. Cont.

\begin{tabular}{|c|c|c|}
\hline RT & Compound Name & Abundance Mean \\
\hline 34.653 & Benzene, 1-(1,5-dimethyl-4-hexenyl)-4-methyl- & 439,300 \\
\hline 35.221 & 6-Octen-1-ol, 3,7-dimethyl-, (R)- & 41,711 \\
\hline 35.225 & Citronellol & 91,789 \\
\hline 35.688 & Ethanol, 2-(2-butoxyethoxy)- & $238,659.5$ \\
\hline 36.222 & 2,6-Octadien-1-ol, 2,7-dimethyl- & 98,600 \\
\hline 36.242 & 2,6-Octadiene, 3,7-dimethyl-1-(2-propenyloxy)- & 208,993 \\
\hline 36.563 & Anethole & 84,862 \\
\hline 36.595 & Estragole & 89,942 \\
\hline 37.181 & p-Mentha-1(7),8-dien-2-ol & 133,232 \\
\hline 37.554 & 1,4-Methanobenzocyclodecene, 1,2,3,4,4a,5,8,9,12,12a-decahydro- & 127,758 \\
\hline 37.742 & Butanoic acid, 3-methyl- & 566,726 \\
\hline 37.757 & Heptanoic acid & 847,338 \\
\hline 37.870 & 2,6-Nonadienal, (E,Z)- & 263,050 \\
\hline 38.143 & 2,5-Pyrrolidinedione, 1-ethyl- & 108,795 \\
\hline 38.328 & Benzyl alcohol & $130,915.5$ \\
\hline 39.218 & Phenylethyl Alcohol & 42,435 \\
\hline 39.663 & Acetic acid, 6,6-dimethyl-2-methylene-7-(3-oxobutylidene)oxepan-3-ylmethyl ester & 76,029 \\
\hline 39.671 & trans-.beta.-Ionone & 110,928 \\
\hline 40.302 & Isoaromadendrene epoxide & 90,637 \\
\hline 40.799 & 11-(2-Cyclopenten-1-yl)undecanoic acid, (+)- & $66,300.5$ \\
\hline 40.980 & Acetic acid, 6,6-dimethyl-2-methylene-7-(3-oxobutylidene)oxepan-3-ylmethyl ester & 79,824 \\
\hline 43.179 & Octanoic acid & $184,543.5$ \\
\hline 46.331 & Phenol, 2-ethyl-4,5-dimethyl- & 50,752 \\
\hline 46.839 & 2,4,6-Octatrien-1-ol, 3,7-dimethyl-(E,E)- & 36,117 \\
\hline 47.457 & 1,2-Cyclohexanediol, 1-methyl-4-(1-methylethenyl)- & 118,730 \\
\hline 47.870 & 2(4H)-Benzofuranone, 5,6,7,7a-tetrahydro-4,4,7a-trimethyl- & $147,328.5$ \\
\hline 48.345 & Cyclobutene, 4,4-dimethyl-1-(2,7-octadienyl)- & 164,733 \\
\hline 49.926 & Benzoic acid & 163,139 \\
\hline
\end{tabular}

Table A8. Results for the EBB sample fingerprint determination with indication of the retention time (RT) and abundance mean for every identified compound.

\begin{tabular}{ccc}
\hline RT & Compound Name & Abundance Mean \\
\hline 0.840 & Glycidol & $75,856.5$ \\
0.950 & .alpha.-Chloroacrylic acid & 59,320 \\
1.530 & 2-Pentanol, 3-chloro-4-methyl-, $\left(R^{*}, R^{*}\right)-(.+/-)-$. & 299,363 \\
1.560 & 1-Methoxy-3-methyl-3-butene & 289,385 \\
3.484 & .beta.-Myrcene & 64,340 \\
5.194 & .beta.-Myrcene & $1,191,105.5$ \\
5.938 & D-Limonene & $4,419,800.5$ \\
6.681 & 3-Hexenal, (Z)- & $472,247.5$ \\
6.964 & N-(Trifluoroacetyl)-N,O,O',O"-tetrakis(trimethylsilyl)norepinephrine & 122,798 \\
7.596 & Tricyclo[2.2.1.0(2,6)]heptane, 1,7,7-trimethyl- & 510,285 \\
7.607 & 4-Carene, (1S,3R,6R)-(-)- & 531,680 \\
8.187 & 1,3,7-Octatriene, 3,7-dimethyl- & $520,381.5$ \\
8.550 & p-Cymene & 182,369 \\
9.023 & $(+)-4-C a r e n e$ & 47,706 \\
10.463 & Dodecane, 2-methyl- & 128,492 \\
10.481 & Nonane & 91,987 \\
10.740 & Undecane, 3,7-dimethyl- & 45,039 \\
11.600 & Sulfurous acid, hexyl pentadecyl ester & 39,988 \\
11.911 & 5-Hepten-2-one, 6-methyl- & 99,068 \\
11.943 & 1-Hepten-6-one, 2-methyl- & 95,405 \\
13.370 & 1-Butanol, 3-methoxy- & $97,327.5$ \\
14.450 & 3-Hexen-1-ol & 49,402 \\
\hline
\end{tabular}


Table A8. Cont.

\begin{tabular}{|c|c|c|}
\hline RT & Compound Name & Abundance Mean \\
\hline 14.475 & 3-Hexen-1-ol, (E)- & 58,769 \\
\hline 14.669 & Nonanal & 112,987 \\
\hline 15.135 & Oxalic acid, allyl tetradecyl ester & 53,901 \\
\hline 15.617 & Decane, 2-methyl- & 41,084 \\
\hline 15.875 & 2-Allyloxy-4,6-bis-phenylsulfanyl-[1,3,5]triazine & 37,390 \\
\hline 15.952 & 3-Decene & 61,937 \\
\hline 15.952 & 1-Hexanol, 3-methyl- & 87,038 \\
\hline 17.110 & 2-Furanmethanol, 5-ethenyltetrahydro-.alpha.,.alpha.,5-trimethyl-, cis- & 46,232 \\
\hline 17.569 & Undecanol-4 & $52,905.5$ \\
\hline 18.168 & Ammonium acetate & 686,834 \\
\hline 18.610 & Furfural & 171,566 \\
\hline 18.646 & Furan-2-carbohydrazide, N2-(1-methylhexylideno)- & 191,841 \\
\hline 19.639 & 3-Oxatricyclo[4.2.0.0(2,4)]octan-7-one & 65,832 \\
\hline 21.010 & Benzaldehyde & $113,463.5$ \\
\hline 21.766 & Tetradecane, 4-ethyl- & 42,793 \\
\hline 22.163 & 1,7-Nonadiene, 4,8-dimethyl- & 635,615 \\
\hline 23.237 & Citronellyl butyrate & 720,225 \\
\hline 23.251 & 1,2-Dihydrolinalool & 778,269 \\
\hline 23.565 & Cyclohexane, 1-methyl-4-(2-hydroxyethyl)- & 104,217 \\
\hline 24.198 & Linalyl acetate & $20,228,501.5$ \\
\hline 24.811 & trans-.alpha.-Bergamotene & 91,781 \\
\hline 25.091 & Fenchol, exo- & 39,940 \\
\hline 25.813 & (+)-(E)-Limonene oxide & 64,200 \\
\hline 27.380 & 3,4-Dimethyl-2-prop-2-enyl-2,5-dihydrothiophene 1,1-dioxide & 66,881 \\
\hline 27.385 & Hotrienol & 67,814 \\
\hline 27.856 & 1-(Phenylmethyl)-1,2,3,6-tetrahydropyridin-3-ol & 122,925 \\
\hline 27.880 & Oxiranemethanol, 2-phenyl- & 180,446 \\
\hline 28.535 & 10-Heptadecen-8-ynoic acid, methyl ester, (E)- & 52,188 \\
\hline 28.960 & 4-Pentenoic acid, 2-acetyl-, ethyl ester & 785,25 \\
\hline 30.035 & 2,6-Octadienal, 3,7-dimethyl-, (Z)- & 367,457 \\
\hline 30.069 & Longipinene epoxide & 249,326 \\
\hline 30.305 & Sulfurous acid, hexyl pentadecyl ester & 200,957 \\
\hline 30.358 & Valeric acid, 3-pentadecyl ester & 89,012 \\
\hline 30.832 & .alpha.-Terpineol & 566,609 \\
\hline 31.429 & .alpha.-Terpineol & $2,871,361$ \\
\hline 31.445 & L-.alpha.-Terpineol & $3,859,251$ \\
\hline 32.063 & $(-)$-Carvone & $168,274.5$ \\
\hline 32.623 & beta.-Bisabolene & 183,784 \\
\hline 32.918 & 2,6-Octadienal, 3,7-dimethyl-, (Z)- & $153,040.5$ \\
\hline 33.281 & 1-Bromo-3,7-dimethyl-2,6-octadiene & 539,860 \\
\hline 33.285 & Linalyl acetate & 735,657 \\
\hline 33.613 & 2H-Pyran-3-ol, 6-ethenyltetrahydro-2,2,6-trimethyl- & 78,347 \\
\hline 33.935 & Propanedioic acid, propyl- & 60,942 \\
\hline 34.239 & Methyl salicylate & 44,184 \\
\hline 34.260 & Tricyclo[7.1.0.0[1,3]]decane-2-carbaldehyde & 53,084 \\
\hline 34.652 & 2,6-Octadien-1-ol, 2,7-dimethyl- & 764,472 \\
\hline 34.935 & 2H-Pyran-3-ol, 6-ethenyltetrahydro-2,2,6-trimethyl- & $93,514.5$ \\
\hline 35.255 & 2-Pentadecyn-1-ol & 70,853 \\
\hline 35.255 & 9,15-Octadecadienoic acid, methyl ester & 47,285 \\
\hline 35.697 & Ethanol, 2-(2-butoxyethoxy)- & $110,812.5$ \\
\hline 36.251 & 2,6-Octadien-1-ol, 2,7-dimethyl- & $618,537.5$ \\
\hline 37.164 & Dihydrocarvyl acetate & 78,561 \\
\hline 37.200 & 2-Cyclohexen-1-ol, 2-methyl-5-(1-methylethenyl)-, acetate, (1R-cis)- & 79,721 \\
\hline 37.889 & trans,cis-2,6-Nonadien-1-ol & $1,039,600$ \\
\hline 37.891 & 2,6-Nonadienal, (E,Z)- & $1,143,942$ \\
\hline 38.153 & 2,5-Pyrrolidinedione, 1-ethyl- & $129,426.5$ \\
\hline 38.335 & Benzyl alcohol & 119,005 \\
\hline 38.380 & Benzene, (2,2-dimethylbutyl)- & 99,835 \\
\hline
\end{tabular}


Table A8. Cont.

\begin{tabular}{ccc}
\hline RT & Compound Name & Abundance Mean \\
\hline 38.721 & Geranyl acetate, 2,3-epoxy- & 163,962 \\
39.235 & Phenylethyl Alcohol & 75,575 \\
39.670 & Acetic acid, 6,6-dimethyl-2-methylene-7-(3-oxobutylidene)oxepan-3-ylmethyl ester & 134,033 \\
40.314 & Isoaromadendrene epoxide & 143,108 \\
40.585 & Pyruvic acid, 3-hexenyl ester & 55,982 \\
40.793 & Myrcenylacetat & 109,085 \\
40.799 & 8,11,14-Eicosatrienoic acid, methyl ester, (Z,Z,Z)- & 96,145 \\
41.084 & 3(10)-Caren-4-ol, acetoacetic acid ester & 176,125 \\
41.087 & 1,6-Octadien-3-ol, 3,7-dimethyl-, 2-aminobenzoate & 179,443 \\
43.193 & Octanoic acid & 54,969 \\
43.780 & Cholestane-3,6,7-triol, (3.beta.,5.alpha.,6.beta.,7.beta.)- & 100,688 \\
44.784 & Cyclododeca-5,9-dien-1-ol, 2-methyl-, (Z,Z)- & 82,400 \\
45.205 & 4-Piperidin-1-yl-6-(4-tetrazol-1-yl-phenoxymethyl)-[1,3,5]triazin-2-ylamine & 59,889 \\
45.626 & 2-Cyclohexen-1-ol, 2-methyl-5-(1-methylethenyl)-, acetate, (1R-cis)- & 111,323 \\
46.351 & Phenol, 2,3,4,6-tetramethyl- & 98,885 \\
47.882 & 2(4H)-Benzofuranone, 5,6,7,7a-tetrahydro-4,4,7a-trimethyl- & $75,435.5$ \\
\hline
\end{tabular}

Table A9. Results for the SBL sample fingerprint determination with indication of the retention time (RT) and abundance mean for every identified compound.

\begin{tabular}{|c|c|c|}
\hline RT & Compound Name & Abundance Mean \\
\hline 1.084 & Acetone & 331,948 \\
\hline 1.185 & 2-Methyl-2-(4-nitrobenzenesulfonamido)propyl N-methylcarbamate & 74,669 \\
\hline 1.210 & Cyclobutane, methylene- & 110,395 \\
\hline 1.270 & Ecgonine, o-pentafluoropropionyl-, pentafluoropropyl ester & 84,216 \\
\hline 1.380 & Tetrahydropyran & 62,535 \\
\hline 1.430 & Diallyl carbonate & 72,075 \\
\hline 1.435 & 2-Propen-1-amine, N-ethyl- & 93,704 \\
\hline 1.605 & Cyclobutaneoctol & 50,049 \\
\hline 3.250 & 2-Propenamide, N-(1-cyclohexylethyl)- & 72,158 \\
\hline 3.285 & Hexanal & 139,699 \\
\hline 3.361 & 1,2,4-Triazole, 4-[N-(2-hydroxyethyl)-N-nitro]amino- & 139,316 \\
\hline 3.555 & beta.-Pinene & 432,956 \\
\hline 3.593 & Cyclohexane, 1-methylene-4-(1-methylethenyl)- & 495,699 \\
\hline 3.855 & 2,6-Octadiene, 3,7-dimethyl-1-(2-propenyloxy)- & 52,281 \\
\hline 3.870 & Pyridine, 2-(4-pyridylmethylenamino)- & 66,726 \\
\hline 4.450 & 2-Keto-3-methylene-5-methyltetrahydrothiophene & 54,550 \\
\hline 5.180 & 1-Pentene, 5-(2,2-dimethylcyclopropyl)-2-methyl-4-methylene- & 61,122 \\
\hline 5.180 & 1,6,10-Dodecatriene, 7,11-dimethyl-3-methylene- & 66,379 \\
\hline 6.024 & D-Limonene & $12,325,691.5$ \\
\hline 6.727 & 2-Hexenal & 147,443 \\
\hline 7.639 & gamma.-Terpinene & $163,504.5$ \\
\hline 7.720 & 2-(3-Methyl-but-1-ynyl)-cyclohexene-1-carboxaldehyde & 77,433 \\
\hline 8.645 & Benzene, 1-methyl-3-(1-methylethyl)- & $824,049.5$ \\
\hline 9.130 & trans-.beta.-Terpinyl butanoate & 54,444 \\
\hline 9.689 & Octanal & $70,984.5$ \\
\hline 10.410 & 6-Chloro-2,2,9,9-tetramethyl-3,7-decadiyn-5-ol & 53,045 \\
\hline 10.838 & Dodecane, 5-methyl- & 66,791 \\
\hline 11.983 & 1-Hepten-6-one, 2-methyl- & 171,591 \\
\hline 12.000 & 5-Hepten-2-one, 6-methyl- & 214,793 \\
\hline 14.540 & 1,3,3-Trimethylcyclopropene & 71,027 \\
\hline 14.763 & Nonanal & 104,120 \\
\hline 16.748 & Cyclobutane, 1,2-bis(1-methylethenyl)-, trans- & $265,149.5$ \\
\hline 17.190 & 2-Furanmethanol, 5-ethenyltetrahydro-.alpha.,.alpha.,5-trimethyl-, cis- & 76,018 \\
\hline 17.211 & cis-5-Methyl-2-isopropyl-2-hexen-1-al & 57,488 \\
\hline 17.412 & Cyclobutane, 1,2-bis(1-methylethenyl)-, trans- & 303,970 \\
\hline
\end{tabular}


Table A9. Cont.

\begin{tabular}{|c|c|c|}
\hline RT & Compound Name & Abundance Mean \\
\hline 18.334 & Ammonium acetate & 216,233 \\
\hline 18.712 & Furfural & 415,801 \\
\hline 19.127 & Octane, 5-ethyl-2-methyl- & 100,177 \\
\hline 19.789 & 2,5-Heptadiene, (E,E)- & 78,358 \\
\hline 20.498 & 1,1-Dodecanediol, diacetate & 57,452 \\
\hline 20.663 & 1-Decene, 4-methyl- & 186,582 \\
\hline 20.683 & 1-Hexanol, 2-ethyl- & 133,849 \\
\hline 21.128 & Benzaldehyde & 193,767 \\
\hline 21.270 & Decane, 3,7-dimethyl- & 126,527 \\
\hline 21.350 & Heptane, 2,3,4-trimethyl- & 67,035 \\
\hline 21.509 & 3,5-Octadien-2-one, (E,E)- & $102,421.5$ \\
\hline 21.858 & Undecane, 3,7-dimethyl- & 115,470 \\
\hline 22.150 & 1-Decanol, 5,9-dimethyl- & 92,827 \\
\hline 22.402 & Cyclobutane, 1,2-bis(1-methylethenyl)-, trans- & 81,623 \\
\hline 22.419 & Cyclohexene, 1-methyl-5-(1-methylethenyl)- & 98,513 \\
\hline 22.829 & 1-Isopropenyl-3-propenylcyclopentane & 124,022 \\
\hline 23.281 & 1,2-Dihydrolinalool & 101,149 \\
\hline 23.317 & Cyclopropanemethanol, .alpha.,2-dimethyl-2-(4-methyl-3-pentenyl)-, [1.alpha.(R*),2.alpha.]- & 113,237 \\
\hline 24.144 & Linalyl acetate & $2,220,364$ \\
\hline 24.430 & 2-Decenal, (Z)- & 162,906 \\
\hline 24.448 & Pentane, 1-(2,2-dibromocyclopropyl)- & 114,649 \\
\hline 25.170 & Oxirane, octyl- & 783,66 \\
\hline 25.384 & 5-Decen-1-ol, acetate, (E)- & 100,866 \\
\hline 25.437 & 1-(1H-Imidazol-2-yl)-ethanone & 92,763 \\
\hline 25.862 & 1H-Pyrrole-2-carboxaldehyde, 1-ethyl- & $56,395.5$ \\
\hline 26.174 & 2-Pentanol, 3-chloro-4-methyl-, $\left(\mathrm{R}^{*}, \mathrm{~S}^{*}\right)-(.+/-$.$) -$ & $245,217.5$ \\
\hline 26.420 & Butyrolactone & 60,795 \\
\hline 27.010 & Sulfurous acid, octyl 2-propyl ester & 85,408 \\
\hline 27.028 & Sulfurous acid, dodecyl 2-propyl ester & 73,132 \\
\hline 30.159 & 2,6-Octadienal, 3,7-dimethyl-, (Z)- & 928,389 \\
\hline 30.420 & 2,5-Dihydroxyheptane & 73,287 \\
\hline 30.480 & Oxetane, 2-ethyl-3-methyl- & 81,149 \\
\hline 30.640 & Thiophene, 3-methylsulfonyl- & 69,756 \\
\hline 30.909 & p-Mentha-1(7),8(10)-dien-9-ol & 143,103 \\
\hline 31.487 & .alpha.-Terpineol & 408,707 \\
\hline 32.192 & (-)-Carvone & $402,266.5$ \\
\hline 33.032 & 2,6-Octadienal, 3,7-dimethyl-, (Z)- & $1,115,315.5$ \\
\hline 33.362 & Linalyl acetate & $167,765.5$ \\
\hline 33.670 & Cyclopropanemethanol, 2-isopropylidene-.alpha.-methyl- & 55,873 \\
\hline 33.949 & cis-p-Mentha-2,8-dien-1-ol & $843,89,5$ \\
\hline 34.711 & 2,6-Octadien-1-ol, 2,7-dimethyl- & 253,900 \\
\hline 34.970 & Cyclohexene, 3-acetoxy-4-(1-hydroxy-1-methylethyl)-1-methyl- & 68,155 \\
\hline 35.301 & Citronellal & $77,794.5$ \\
\hline 35.581 & p-Mentha-1(7),8(10)-dien-9-ol & 51,607 \\
\hline 36.309 & beta.-Myrcene & $76,695.5$ \\
\hline 36.649 & 1-Heptadec-1-ynyl-cyclohexanol & 86,850 \\
\hline 36.697 & 5-Isopropenyl-1,2-dimethylcyclohex-2-enol & 50,040 \\
\hline 37.261 & trans-p-mentha-1(7),8-dien-2-ol & 262,206 \\
\hline 37.270 & Carveol & 221,405 \\
\hline 37.820 & Butanoic acid, 3-methyl- & $378,023.5$ \\
\hline 37.943 & .beta.-Myrcene & 279,721 \\
\hline 38.222 & 2,5-Pyrrolidinedione, 1-ethyl- & $221,432.5$ \\
\hline 38.401 & Benzyl alcohol & 196,719 \\
\hline 38.417 & Benzene, [(2-propenyloxy)methyl]- & 158,666 \\
\hline 38.773 & 3-hydroxy-2-methyl-5-(prop-1-en-2-yl)cyclohexanone & 108,854 \\
\hline 39.288 & Phenylethyl Alcohol & 64,612 \\
\hline 39.733 & Acetic acid, 6,6-dimethyl-2-methylene-7-(3-oxobutylidene)oxepan-3-ylmethyl ester & 71,831 \\
\hline
\end{tabular}


Table A9. Cont.

\begin{tabular}{cc}
\hline RT & Compound Name \\
\hline 39.739 & trans-.beta.-Ionone \\
40.358 & Cyclododeca-5,9-dien-1-ol, 2-methyl-, $(Z, Z)-$ \\
40.850 & 1-Ethynyl-1-cyclooctanol \\
41.063 & Acetic acid, 2,6,6-trimethyl-3-methylene-7-(3-oxobutylidene)oxepan-2-yl ester \\
43.248 & Octanoic acid \\
43.765 & Triacetin \\
47.941 & $2(4 \mathrm{H})$-Benzofuranone, 5,6,7,7a-tetrahydro-4,4,7a-trimethyl- \\
\hline
\end{tabular}

Table A10. Results for the TBC sample fingerprint determination with indication of the retention time (RT) and abundance mean for every identified compound.

\begin{tabular}{|c|c|c|}
\hline RT & Compound Name & Abundance Mean \\
\hline 0.715 & Acetic acid, cyano- & 58,385 \\
\hline 0.814 & Acetic acid, cyano- & 41,951 \\
\hline 0.890 & Disulfide, isopentyl methyl & 32,293 \\
\hline 0.891 & 5-Aminoisoxazole & 77,786 \\
\hline 0.967 & Thiocyanic acid, 5-amino-3-methyl-4-isoxazolyl ester & 59,100 \\
\hline 0.970 & 3-Butynoic acid & 63,100 \\
\hline 1.083 & Isobutyl nitrite & 180,084 \\
\hline 1.086 & Propanal, 2-methyl- & 118,133 \\
\hline 1.305 & 1,4-Dioxane, 2,5-dimethyl- & 52,275 \\
\hline 1.319 & 4-Oxa-6-hepten-2-one, 6-bromo-3-methyl- & 76,789 \\
\hline 1.452 & Oxalic acid, butyl propyl ester & 205,128 \\
\hline 1.486 & Butanal, 2-methyl- & 454,443 \\
\hline 1.495 & Oxirane, trimethyl- & 64,342 \\
\hline 1.520 & Neburon & 152,396 \\
\hline 1.590 & Carbonic acid, allyl 2-ethoxyethyl ester & 85,342 \\
\hline 1.690 & Carbonic acid, allyl isohexyl ester & 65,883 \\
\hline 1.695 & 1,2-Pentadiene, 4,4-dimethyl- & 47,310 \\
\hline 1.750 & 2-Oxazolamine, 4,5-dihydro-5-(phenoxymethyl)- & 50,644 \\
\hline 1.998 & Butanal, 3-methyl- & 97,682 \\
\hline 2.602 & Octane, 2,3,6,7-tetramethyl- & 46,275 \\
\hline 3.302 & Hexanal & $153,104.5$ \\
\hline 3.375 & (1RS)-propanol, 1-cyano-(2S)-(tert.butyloxycarbonyl)amino- & 62,614 \\
\hline 3.450 & 4-Chloro-3-methylbut-2-en-1-ol & 101,437 \\
\hline 3.485 & 3,4-Dimethylcyclohexanol & 42,683 \\
\hline 5.165 & Cyclopropanemethanol, 2-isopropylidene-.alpha.-methyl- & 42,196 \\
\hline 5.219 & Sulfide, cyclopentyl isopropyl & 70,260 \\
\hline 6.045 & 3-Cyclohexene-1-methanol, .alpha.,.alpha.,4-trimethyl-, acetate & 33,625 \\
\hline 6.732 & 2-Hexenal & 213,047 \\
\hline 6.744 & 3-Hexenal, (Z)- & 523,559 \\
\hline 6.760 & Heptanonitrile & 257,029 \\
\hline 6.998 & 2,6-Nonadienal, (E,Z)- & 40,726 \\
\hline 7.370 & Homopiperazine & 32,993 \\
\hline 8.270 & 4-Methyl-2-oxopentanenitrile & 45,025 \\
\hline 8.297 & 1-Pentanol & 91,705 \\
\hline 8.478 & Sulfurous acid, hexyl octyl ester & 64,375 \\
\hline 8.941 & Cyclohexane, 1,2,4-tris(methylene)- & 30,691 \\
\hline 10.065 & 1,3-Pentanedione, 2,4-dimethyl-1-phenyl- & 50,566 \\
\hline 11.997 & 1-Hepten-6-one, 2-methyl- & 43,920 \\
\hline 12.959 & Spiro[3.5]nona-5,7-dien-1-one, 5,9,9-trimethyl- & 40,729 \\
\hline 13.104 & 2-Trifluoroacetoxydodecane & 38,203 \\
\hline 14.530 & Cycloheptano[d]imidazolidine, 1,3-dihydroxy-2-methyl- & 73,913 \\
\hline 14.567 & 3-Hexen-1-ol, (E)- & $106,729.5$ \\
\hline
\end{tabular}


Table A10. Cont.

\begin{tabular}{|c|c|c|}
\hline RT & Compound Name & Abundance Mean \\
\hline 14.605 & 1,3,2-Dioxaphospholane, 2-cyclohexyl-4,5-dimethyl- & 56,722 \\
\hline 14.720 & 1-Cyclohexylethanol & 38,396 \\
\hline 14.763 & Nonanal & 119,865 \\
\hline 14.770 & 1,2,4-Triazol-5-acetic acid, 3-amino- & 50,306 \\
\hline 14.805 & 5-t-Butyl-cycloheptene & 36,888 \\
\hline 15.219 & Oxirane, 2-butyl-3-methyl-, cis- & 47,050 \\
\hline 15.665 & 3,6-Heptanedione & 166,183 \\
\hline 15.694 & Dodecane, 2-methyl- & 406,601 \\
\hline 15.706 & Decane, 2,4-dimethyl- & 203,345 \\
\hline 15.790 & 2-Furannonanoic acid, 5-(21,23-dimethylpentacosyl)tetrahydro-, methyl ester & 45,108 \\
\hline 15.825 & Piperidine-4-carboxamide, 1-(3,4,5-trimethoxybenzoyl)- & 47,258 \\
\hline 15.845 & 5-Bromo-1-hexene & 75,733 \\
\hline 15.885 & .alpha.-Chlorocyclooctanone oxime & 66,635 \\
\hline 15.910 & 7-Octenoic acid, methyl ester & 39,237 \\
\hline 16.203 & Benzene, 1-ethyl-3,5-dimethyl- & 41,469 \\
\hline 18.342 & Ammonium acetate & 102,343 \\
\hline 18.415 & Acetic acid & 64,804 \\
\hline 18.729 & 2-Nonenal, 8-oxo- & 173,371 \\
\hline 18.749 & 4-Pentenoic acid, 2-methylene-, methyl ester & 182,615 \\
\hline 18.785 & 6-Tetradecanol & 49,218 \\
\hline 20.671 & 1-Hexanol, 2-ethyl- & 721,868 \\
\hline 21.081 & Benzaldehyde & $163,232.5$ \\
\hline 21.305 & 3(2H)-Furanone, dihydro-5-isopropyl- & 65,684 \\
\hline 21.495 & 1,3-Butanedione, 1-(2-furanyl)- & 55,641 \\
\hline 23.285 & Citronellyl butyrate & 39,321 \\
\hline 24.110 & Linalyl acetate & 840,872 \\
\hline 24.413 & Octanal & 45,631 \\
\hline 24.423 & Cyclopropane, 1-heptyl-2-methyl- & 64,716 \\
\hline 25.172 & Oxirane, dodecyl- & $94,251.5$ \\
\hline 26.065 & 3-Isopropylidene-5-methyl-hex-4-en-2-one & 33,496 \\
\hline 26.418 & Butyrolactone & 47,210 \\
\hline 27.021 & Decane, 2,4,6-trimethyl- & 80,426 \\
\hline 27.023 & Sulfurous acid, dodecyl 2-propyl ester & 91,716 \\
\hline 27.940 & 2,4,6-Cycloheptatrien-1-one, 4-methyl- & 88,296 \\
\hline 28.746 & Tricyclo[3.3.1.1(3,7)]decane, 2-nitro- & $276,194.5$ \\
\hline 29.028 & Dispiro[4.2.4.2]tetradecane & 72,071 \\
\hline 29.038 & Tricyclo[3.3.1.1(3,7)]decane, 2-nitro- & 117,874 \\
\hline 30.175 & 1,3-Pentadiene, 5-(2,2-dimethylcyclopropyl)-2,4-dimethyl-, ( $\mathrm{Z}$ or E)- & 60,534 \\
\hline 30.229 & .alpha.-Chlorocyclooctanone oxime & 35,753 \\
\hline 30.524 & Aziridinone, 1-(1,1-dimethylethyl)-3-tricyclo[3.3.1.1(3,7)]dec-1-yl- & 73,998 \\
\hline 30.533 & 8,11,14-Eicosatrienoic acid, methyl ester, $(\mathrm{Z}, \mathrm{Z}, \mathrm{Z})-$ & 93,089 \\
\hline 31.424 & .alpha.-Terpineol & 47,609 \\
\hline 32.351 & Dispiro[4.2.4.2] tetradecane & $367,543.5$ \\
\hline 33.945 & Pentanoic acid & 44,424 \\
\hline 34.295 & Methyl salicylate & $132,619.5$ \\
\hline 34.425 & Benzenamine, N-[4-(1-methylethyl)benzylidene]-4-(1-pyrrolidylsulfonyl)- & 40,434 \\
\hline 34.685 & 2,6-Octadien-1-ol, 2,7-dimethyl- & 93,110 \\
\hline 34.986 & Cyclopropanemethanol, 2-isopropylidene-.alpha.-methyl- & 81,101 \\
\hline 35.015 & 2H-Pyran-3-ol, 6-ethenyltetrahydro-2,2,6-trimethyl- & 107,522 \\
\hline 35.648 & 1-Phenyl-2-butanone & $77,853.5$ \\
\hline 37.437 & 1,4-Methanobenzocyclodecene, $1,2,3,4,4 a, 5,8,9,12,12 \mathrm{a}$-decahydro- & $182,739.5$ \\
\hline 37.818 & Heptanoic acid & 327,611 \\
\hline 37.826 & Formic acid, 2-methylpropyl ester & 270,250 \\
\hline 38.221 & 2,5-Pyrrolidinedione, 1-ethyl- & $111,221.5$ \\
\hline 38.402 & Benzyl-diseryl phosphate & 132,761 \\
\hline 38.403 & Benzyl alcohol & 126,413 \\
\hline 39.052 & Pregnane-3,8,12,14,17,20-hexol, (3.beta.,5.alpha.,12.beta.,14.beta.,17.alpha.,20S)- & 34,151 \\
\hline
\end{tabular}


Table A10. Cont.

\begin{tabular}{ccc}
\hline RT & Compound Name & Abundance Mean \\
\hline 39.285 & Phenylethyl Alcohol & 55,509 \\
39.726 & trans-.beta--Ionone & 77,701 \\
39.727 & 3-Buten-2-one, 4-(2,6,6-trimethyl-1-cyclohexen-1-yl)- & 97,960 \\
40.852 & 11-(2-Cyclopenten-1-yl)undecanoic acid, (+)- & 52,398 \\
41.019 & Pentane, 2-bromo- & 31,014 \\
41.044 & Acetic acid, 6,6-dimethyl-2-methylene-7-(3-oxobutylidene)oxepan-3-ylmethyl ester & 78,871 \\
43.085 & 3-Hepten-2-one, O-methyloxime & 33,472 \\
44.698 & 1,5-Hexadiene, 2,5-dipropyl- & 38,397 \\
47.938 & 2(4H)-Benzofuranone, 5,6,7,7a-tetrahydro-4,4,7a-trimethyl- & 105,392 \\
52.435 & Methyl 4,6-benzylidene-3-deoxy-4-hexopyranoside & 41,183 \\
52.725 & 2-(Imidazole-1-sulfonyl)-benzoic acid methyl ester & 34,590 \\
\hline
\end{tabular}

Table A11. Results for the WBL sample fingerprint determination with indication of the retention time (RT) and abundance mean for every identified compound.

\begin{tabular}{|c|c|c|}
\hline RT & Compound Name & Abundance Mean \\
\hline 0.103 & Borane carbonyl & 72,523 \\
\hline 0.770 & Acetic acid, cyano- & 119,964 \\
\hline 0.840 & aS-Triazine-3,5(2H,4H)-dione, 6-(dimethylamino)- & 109,600 \\
\hline 1.096 & Acetone & 194,968 \\
\hline 2.590 & Benzeneacetic acid, 2-tetradecyl ester & 142,487 \\
\hline 3.265 & Hexanal & $1,020,449$ \\
\hline 3.455 & Allyl trifluoroacetate & 100,639 \\
\hline 6.689 & 2-Hexenal & $165,126.5$ \\
\hline 6.982 & $\mathrm{~N}$-(Trifluoroacetyl)-N,O,O', $\mathrm{O}^{\prime \prime}$-tetrakis(trimethylsilyl)norepinephrine & $474,946.5$ \\
\hline 8.491 & Dodecane, 4-methyl- & 154,490 \\
\hline 8.511 & Octane, 5-ethyl-2-methyl- & 209,142 \\
\hline 9.656 & Octanal & 133,742 \\
\hline 10.964 & 2-Heptenal, (Z)- & $132,743.5$ \\
\hline 11.957 & 5-Hepten-2-one, 6-methyl- & $3,391,388$ \\
\hline 12.325 & trans-Rose oxide & 65,810 \\
\hline 14.753 & Nonanal & 36,0131 \\
\hline 15.167 & trans,cis-2,6-Nonadien-1-ol & $166,441.5$ \\
\hline 18.350 & Ammonium acetate & $1,197,691.5$ \\
\hline 18.705 & Furfural & 245,261 \\
\hline 19.132 & Nonane, 5-(1-methylpropyl)- & 192,955 \\
\hline 19.135 & Tetradecane, 4-methyl- & 137,144 \\
\hline 20.725 & Tridecane, 6-methyl- & 108,712 \\
\hline 21.129 & Benzaldehyde & $309,445.5$ \\
\hline 21.375 & Nonane, 5-(2-methylpropyl)- & 90,406 \\
\hline 24.145 & 5-Hepten-1-ol, 2-ethenyl-6-methyl- & $355,464,5$ \\
\hline 24.473 & 1-Octanol & 104,288 \\
\hline 24.493 & 1-Nonene & 128,456 \\
\hline 25.494 & (S)-(-)-1,2,4-Butanetriol, 2-acetate & 89,072 \\
\hline 25.844 & $2(5 \mathrm{H})$-Furanone, 5,5-dimethyl- & 107,360 \\
\hline 26.274 & (S)-(+)-1,2-Propanediol & $3,130,504$ \\
\hline 26.282 & R-(-)-1,2-propanediol & $3,474,497$ \\
\hline 27.054 & Sulfurous acid, 2-propyl undecyl ester & 407,374 \\
\hline 28.037 & Acetophenone & 134,811 \\
\hline 28.823 & Dodecane, 2,5-dimethyl- & 90,189 \\
\hline 30.205 & 2,6-Octadien-1-ol, 2,7-dimethyl- & 224,600 \\
\hline 30.445 & Nonane, 4,5-dimethyl- & 125,045 \\
\hline 30.657 & Verbenol & 121,652 \\
\hline 31.525 & .alpha.-Terpineol & 345,922 \\
\hline 31.755 & 2'-Ethyl-3-[(3-phenylpropionyl)hydrazono]butyranilide & 86,101 \\
\hline 32.640 & Tetradecane & 365,951 \\
\hline
\end{tabular}


Table A11. Cont.

\begin{tabular}{|c|c|c|}
\hline RT & Compound Name & Abundance Mean \\
\hline 32.666 & Eicosane, 10-methyl- & 386,657 \\
\hline 33.025 & 2,6-Octadienal, 3,7-dimethyl-, (Z)- & 132,753 \\
\hline 34.015 & Pentanoic acid & 82,703 \\
\hline 34.325 & Oxalic acid, octadecyl propyl ester & 88,447 \\
\hline 34.377 & 2-methyltetracosane & 115,659 \\
\hline 34.697 & 2-Dodecenal, (E)- & 163,451 \\
\hline 34.697 & Oxalic acid, propyl tridecyl ester & 104,743 \\
\hline 34.945 & 4-Methyl-2-oxopentanenitrile & 101,744 \\
\hline 35.141 & Heptadecane, 2,6,10,14-tetramethyl- & 101,875 \\
\hline 35.145 & Nonadecane, 2-methyl- & 124,979 \\
\hline 35.319 & 6-Octen-1-ol, 3,7-dimethyl-, (R)- & $507,414.5$ \\
\hline 35.505 & Hexadecane, 2-methyl- & 83,391 \\
\hline 35.506 & Heptadecane, 3-methyl- & 103,232 \\
\hline 35.765 & Ethanol, 2-(2-butoxyethoxy)- & $106,602.5$ \\
\hline 36.134 & Eicosane & 155,798 \\
\hline 36.343 & 2,6-Octadien-1-ol, 2,7-dimethyl- & 242,610 \\
\hline 36.468 & Cyclohexane, eicosyl- & 249,746 \\
\hline 36.651 & Eicosane, 10-methyl- & $298,746.5$ \\
\hline 37.665 & 1,4-Methanobenzocyclodecene, $1,2,3,4,4 a, 5,8,9,12,12 a-d e c a h y d r o-$ & $72,802.5$ \\
\hline 37.838 & Hexanoic acid & 886,987 \\
\hline 37.953 & 1-Bromo-3,7-dimethyl-2,6-octadiene & $1,140,624.5$ \\
\hline 38.241 & 2,5-Pyrrolidinedione, 1-ethyl- & $368,554.5$ \\
\hline 38.419 & Benzyl-diseryl phosphate & 533,200 \\
\hline 38.420 & Benzyl alcohol & 754,339 \\
\hline 38.705 & Thiazolo[3,2-a]pyridinium, 3-hydroxy-2-methyl-, acetate & 92,220 \\
\hline 38.915 & Methanesulfonylacetic acid & 98,645 \\
\hline 39.303 & Phenylethyl Alcohol & 91,829 \\
\hline 39.585 & Octane, 2,3,3-trimethyl- & 109,959 \\
\hline 39.596 & Nonadecane, 2-methyl- & 159,690 \\
\hline 40.285 & Benzene, (1-butyloctyl)- & 115,894 \\
\hline 40.540 & Creosol & $139,225.5$ \\
\hline 40.715 & Hexanoic acid, 2-ethyl- & 155,344 \\
\hline 40.754 & Heptanoic acid & 284,358 \\
\hline 40.871 & Ethanone, 1-(1H-pyrrol-2-yl)- & $163,370.5$ \\
\hline 41.055 & Pregan-20-one, 2-hydroxy-5,6-epoxy-15-methyl- & 107,105 \\
\hline 41.205 & Pentafluoropropionic acid, decyl ester & 85,453 \\
\hline 41.425 & m-Toluic acid, 2-ethylcyclohexyl ester & 84,728 \\
\hline 41.847 & Benzaldehyde, 4-methoxy- & $534,873.5$ \\
\hline 42.365 & 3-Isopropylidene-5-methyl-hex-4-en-2-one & 103,040 \\
\hline 42.505 & (+)-3-Carene, 10-(acetylmethyl)- & 66,804 \\
\hline 43.255 & Octanoic acid & $3,876,198$ \\
\hline 44.623 & 2-Pentadecanone, 6,10,14-trimethyl- & 225,638 \\
\hline 44.755 & 2,6-Octadiene-1,8-diol, 2,6-dimethyl- & 63,621 \\
\hline 44.755 & p-Mentha-1,8-dien-7-yl acetate & 96,497 \\
\hline 45.306 & 3-Ethyl-1-heptyne-3-ol & $106,999.5$ \\
\hline 45.515 & n-Hexadecanoic acid & 282,887 \\
\hline 45.899 & .alpha.-Bulnesene & 79,896 \\
\hline 46.293 & Cycloheptane, 4-methylene-1-methyl-2-(2-methyl-1-propen-1-yl)-1-vinyl- & 87,168 \\
\hline 46.294 & $(-)$-Isolongifolol, acetate & 122,326 \\
\hline 46.424 & 2-(p-Tolylmethyl)-p-xylene & 171,310 \\
\hline 46.430 & Ethane, 1-(o-ethylphenyl)-1-phenyl- & 144,701 \\
\hline 47.579 & Pyrrole-2-carboxylic acid, 4-(1-chlorodec-1-enyl)-3,5-dimethyl-, ethyl ester & 98,928 \\
\hline 47.605 & n-Decanoic acid & $2,589,191$ \\
\hline 47.940 & 2(4H)-Benzofuranone, 5,6,7,7a-tetrahydro-4,4,7a-trimethyl- & $416,391.5$ \\
\hline 50.353 & Benzophenone & 885,368 \\
\hline 51.520 & Vanillin & 684,992 \\
\hline 52.990 & 1,2-Benzenedicarboxylic acid, butyl 2-ethylhexyl ester & 304,646 \\
\hline 52.991 & 1,2-Benzenedicarboxylic acid, bis(2-methylpropyl) ester & 390,059 \\
\hline
\end{tabular}




\section{References}

1. Uhl, W.J. L'Arte del Tè, Guida Alla Selezione, Infusione e Presentazione Di Tè Squisiti, 1st ed.; Il Castello: Milan, Italy, 2017.

2. Deka, H.; Barman, T.; Dutta, J.; Devi, A.; Tamuly, P.; Paul, R.K.; Karak, T. Catechin and caffeine content of tea (Camellia sinensis L.) leaf significantly differ with seasonal variation: A study on popular cultivars in North East India. J. Food Compos. Anal. 2020, 103684. [CrossRef]

3. Yu, L.; Wang, S.; Li, T.; Han, L. Response of soil faunal communities to tea tree cultivars in the hilly region of western Sichuan, China. Sci. Hortic. 2021, 275, 109701. [CrossRef]

4. Wang, M.; Bai, Y.; Wang, Z.; Zhang, Z.; Liu, D.; Lian, X. Higher tea consumption is associated with decreased risk of small vessel stroke. Clin. Nutr. 2020. [CrossRef] [PubMed]

5. Ody, P. Complete Guide to Medicinal Herbs, 2nd ed.; Dorling Kindersley Publishing: London, UK, 2008 ; pp. 48-53.

6. Zhang, P.; Wang, W.; Liu, X.-H.; Yang, Z.; Gaur, R.; Wang, J.-J.; Ke, J.-P.; Bao, G.-H. Detection and quantification of flavoalkaloids in different tea cultivars and during tea processing using UPLC-TOF-MS/MS. Food Chem. 2021, 339, 127864. [CrossRef] [PubMed]

7. Wang, J.L.J.; Yao, Y.; Hua, J.; Zhou, Q.; Jiang, Y.; Deng, Y.; Yang, Y.; Wang, J.; Yuan, H.; Dong, C. Phytochemical comparison of different tea (Camellia sinensis) cultivars and its association with sensory quality of finished tea. LWT 2020, 117, 108595. [CrossRef]

8. Zhang, Y.; Wang, L.; Wei, K.; Ruan, L.; Wu, L.; He, M.; Tong, H.; Cheng, H. Differential regulatory mechanisms of secondary metabolites revealed at different leaf positions in two related tea cultivars. Sci. Hortic. 2020, 270, 109579. [CrossRef]

9. Okakura, K. Il Libro del Tè, 1st ed.; Garzanti: Milan, Italy, 2016.

10. Mu, B.; Zhu, B.; Lv, H.-P.; Yan, H.; Peng, Q.-H.; Lin, Z. The enantiomeric distributions of volatile constituents in different tea cultivars. Food Chem. 2018, 265, 329-336. [CrossRef]

11. Zhao, Y.; Lai, W.; Xu, A.; Jin, J.; Wang, Y.; Xu, P. Characterizing relationships among chemicals, sensory attributes and in vitro bioactivities of black tea made from an anthocyanins-enriched tea cultivar. LWT 2020, 132, 109814. [CrossRef]

12. Liao, X.; Yan, J.; Wang, B.; Meng, Q.; Zhang, L.; Tong, H. Identification of key odorants responsible for cooked corn-like aroma of green teas made by tea cultivar 'Zhonghuang 1'. Food Res. Int. 2020, 136, 109355. [CrossRef]

13. Ji, H.-G.; Lee, Y.-R.; Lee, M.-S.; Hwang, K.-H.; Kim, E.-H.; Park, J.-S.; Hong, Y.-S. Metabolic phenotyping of various tea (Camellia sinensis L.) cultivars and understanding of their intrinsic metabolism. Food Chem. 2017, 233, 321-330. [CrossRef]

14. Wang, C.; Zhang, C.; Kong, Y.; Peng, X.; Li, C.; Liu, S.; Du, L.; Xiao, D.; Xu, Y. A comparative study of volatile components in Dianhong teas from fresh leaves of four tea cultivars by using chromatography-mass spectrometry, multivariate data analysis, and descriptive sensory analysis. Food Res. Int. 2017, 100, 267-275. [CrossRef]

15. Ye, N.; Zhang, L.; Gu, X. Discrimination of Green Teas from Different Geographical Origins by Using HS-SPME/GC-MS and Pattern Recognition Methods. Food Anal. Methods 2012, 5, 856-860. [CrossRef]

16. Il Mondo del Tè. Available online: https://mondodelte.wordpress.com/2014/09/10/icomposti-chimici-nel-te/ (accessed on 30 June 2020).

17. Zheng, X.-Q.; Li, Q.-S.; Xiang, L.-P.; Liang, Y.-R. Recent Advances in Volatiles of Teas. Molecules 2016, 21, 338. [CrossRef]

18. Collings, E.R.; Alamar, M.C.; Redfern, S.; Cools, K.; Terry, L.A. Spatial changes in leaf biochemical profile of two tea cultivars following cold storage under two different vapour pressure deficit (VPD) conditions. Food Chem. 2019, 277, 179-185. [CrossRef]

19. Han, Z.-X.; Rana, M.-M.; Liu, G.-F.; Gao, M.-J.; Li, D.-X.; Wu, F.-G.; Li, X.-B.; Wan, X.-C.; Wei, S. Data on green tea flavor determinantes as affected by cultivars and manufacturing processes. Data Brief 2017, 10, 492-498. [CrossRef]

20. Abbatangelo, M.; Núñez-Carmona, E.; Sberveglieri, V.; Zappa, D.; Comini, E.; Sberveglieri, G. Application of a Novel S3 Nanowire Gas Sensor Device in Parallel with GC-MS for the Identification of Rind Percentage of Grated Parmigiano Reggiano. Sensors 2018, 18, 1617. [CrossRef]

21. Núñez-Carmona, E.; Abbatangelo, M.; Sberveglieri, V. Innovative Sensor Approach to Follow Campylobacter jejuni Development. Biosensors 2019, 9, 8. [CrossRef] [PubMed]

22. Abbatangelo, M.; Núñez-Carmona, E.; Duina, G.; Sberveglieri, V.; Núñez-Carmona, E. Multidisciplinary Approach to Characterizing the Fingerprint of Italian EVOO. Molecules 2019, 24, 1457. [CrossRef]

23. Núñez-Carmona, E.; Abbatangelo, M.; Zottele, I.; Piccoli, P.; Tamanini, A.; Comini, E.; Sberveglieri, G.; Sberveglieri, V. Nanomaterial Gas Sensors for Online Monitoring System of Fruit Jams. Foods 2019, 8, 632. [CrossRef]

24. Sberveglieri, V.; Bhandari, M.P.; Carmona, E.N.; Betto, G.; Sberveglieri, G. A novel MOS nanowire gas sensor device (S3) and GC-MS-based approach for the characterization of grated Parmigiano Reggiano cheese. Biosensors 2016, 6, 60. [CrossRef]

25. Sberveglieri, G. Recent developments in semiconducting thin-film gas sensors. Sens. Actuators B Chem. 1995, $23,103-109$. [CrossRef]

26. Comini, E.; Ottini, L.; Faglia, G.; Sberveglieri, G. SnO 2 RGTO UV Activation for CO Monitoring. IEEE Sens. J. 2004, 4, 17-20. [CrossRef]

27. Dieguez, A.; Romano-Rodriguez, A.; Morante, J.; Sangaletti, L.; Depero, L.E.; Comini, E.; Faglia, G.; Sberveglieri, G. Influence

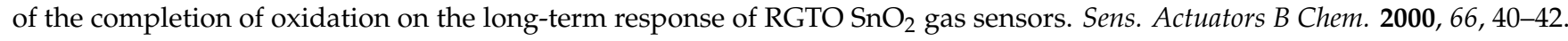
[CrossRef]

28. Comini, E.; Faglia, G.; Sberveglieri, G.; Pan, Z.; Wang, Z.L. Stable and highly sensitive gas sensors based on semiconducting oxide nanobelts. Appl. Phys. Lett. 2002, 81, 1869-1871. [CrossRef]

29. Sberveglieri, G.; Concina, I.; Comini, E.; Falasconi, M.; Ferroni, M.; Sberveglieri, V. Synthesis and integration of tin oxide nanowires into an electronic nose. Vacuum 2012, 86, 532-535. [CrossRef] 
30. Zappa, D.; Comini, E.; Zamani, R.; Arbiol, J.; Morante, J.; Sberveglieri, G. Preparation of copper oxide nanowire-based conductometric chemical sensors. Sens. Actuators B Chem. 2013, 182, 7-15. [CrossRef]

31. Abbatangelo, M.; Núñez-Carmona, E.; Sberveglieri, V. Application of a novel S3 nanowire gas sensor device in parallel with GC-MS for the identification of Parmigiano Reggiano from US and European competitors. J. Food Eng. 2018, 236, 36-43. [CrossRef]

32. Abbatangelo, M.; Núñez-Carmona, E.; Sberveglieri, V. Novel equipment for food quality control: An IoT nanowire gas sensors array. Chem. Eng. Trans. 2019, 75, 25-30.

33. Yannai, S. Dictionary of Food Compounds with CD-ROM, 2nd ed.; CRC Press: Boca Raton, FL, USA, 2012.

34. Burdock, G.A. Fenaroli's Handbook of Flavor Ingredients, 5th ed.; CRC Press: Boca Raton, FL, USA, 2005. 